\title{
Transarterial radioembolization using yttrium-90 microspheres in the treatment of hepatocellular carcinoma: a review on clinical utility and developments
}

\author{
This article was published in the following Dove Press journal: \\ Journal of Hepatocellular Carcinoma \\ 3 November 2014 \\ Number of times this article has been viewed
}

\section{Alberta Cappelli ${ }^{1}$ \\ Cinzia Pettinato ${ }^{2}$ \\ Rita Golfieri'}

'Radiology Unit, ${ }^{2}$ Medical Physics Unit, Department of Medical and Surgical Sciences, Alma Mater Studiorum University of Bologna, S OrsolaMalpighi Hospital, Bologna, Italy
Correspondence: Alberta Cappelli Radiology Unit, Department of Medical and Surgical Sciences, Alma Mater Studiorum - University of Bologna, S Orsola-Malpighi Hospital, Via Albertoni, I5, 40I38 Bologna, Italy Tel $+3905 \mid 6362598$ $\mathrm{Fax}+390516362699$ Email alberta.cappelli@aosp.bo.it
Abstract: A selective intra-arterial liver injection using yttrium-90-loaded microspheres as sources for internal radiation therapy is a form of transarterial radioembolization (TARE). Current data from the literature suggest that TARE is effective in hepatocellular carcinoma (HCC) and is associated with a low rate of adverse events; however, they are all based on retrospective series or non-controlled prospective studies, since randomized controlled trials comparing the other liver-directed therapies for intermediate and locally advanced stages HCC are still ongoing. The available data show that TARE provides similar or even better survival rates. TARE is very well tolerated and has a low rate of complications; these complications do not result from the embolic effects but mainly from the unintended irradiation to non-target tissue, including the liver parenchyma. The complications can be further reduced by accurate patient selection and a strict pre-treatment evaluation, including dosimetry and assessment of the vascular anatomy. First-line TARE is best indicated for intermediate-stage patients (according to the Barcelona Clinic Liver Cancer [BCLC] staging classification) who are poor candidates for transarterial chemoembolization or patients having locally advanced disease with segmental or lobar branch portal vein thrombosis. Moreover, data are emerging regarding the use of TARE in patients classified slightly above the criteria for liver transplantation with the purpose of downstaging them. TARE can also be applied as a second-line treatment in patients progressing to transarterial chemoembolization or sorafenib; a large number of Phase II/III trials are in progress in order to evaluate the best association with systemic therapies. Given the complexity of a correct treatment algorithm for potential TARE candidates and the need for clinical guidance, a comprehensive review was carried out analyzing both the best selection criteria of patients who really benefit from TARE and the new advances of this therapy which add significant value to the therapeutic weaponry against HCC.

Keywords: radioembolization, yttrium-90, hepatocellular carcinoma

\section{Background}

Hepatocellular carcinoma (HCC) is the sixth most common malignancy worldwide, with more than 700,000 cases diagnosed yearly; ${ }^{1}$ it is also the third most common cause of cancer-related mortality. ${ }^{2,3}$ Despite substantial progress in the diagnosis and treatment of HCC, suboptimal treatment results are frequently reported in the intermediate/advanced stages, and the disease is very difficult to control when it presents in the advanced stage., ${ }^{4,5}$

The current staging system, the Barcelona Clinic Liver Cancer (BCLC) staging classification suggests TACE (TACE) is the standard of care for the management 
of intermediate HCC (BCLC-B stage). On the other hand, systemic therapies may be effective in advanced $\mathrm{HCC}$ with distant metastasis and/or vascular invasion (BCLC-C stage). ${ }^{6,7}$

Even though a systematic review by Llovet et $\mathrm{al}^{8}$ has reported an increased survival rate in patients treated with TACE, the low efficacy of this treatment has been demonstrated in cases of large multinodular tumors. ${ }^{9,10}$

Regarding sorafenib, a receptor tyrosine kinase inhibitor, two large randomized trials, ${ }^{11,12}$ together with other studies, ${ }^{13-15}$ have reported a benefit in terms of survival rate.

However, one problem which emerged is that, in a subsequent subanalysis of these trials, it was discovered that the tolerability of sorafenib was suboptimal; it was downdosed in more than half of the patients and interrupted in $45 \%$ of patients due to severe adverse events (AEs) or liver function deterioration. ${ }^{16}$

Moreover, it has been well demonstrated that more than two-thirds of HCC patients die from intrahepatic progression or liver failure rather than from metastatic disease, ${ }^{17-21}$ and that improvement of time to tumor progression (TTP) and overall survival (OS) are not effective in some settings.

This scenario has led to new therapies for the optimal management of intermediate/advanced-stage HCC and, in this setting, available data have shown that transarterial radioembolization (TARE) could be an effective therapeutic option.

The present review mainly summarizes the recent results of TARE regarding tumor response, survival rates, adverse events, and safety.

The utility of this therapy in terms of patients' survival rate will be focused on with the aim of providing its correct use in daily practice and for conducting valid clinical trials on patients with intermediate/locally advanced-stage HCC. The aspects of dosimetry concerning tumor response and safety according to the new advances were also reviewed in detail and the future direction for this technology was discussed. The optimal use of this therapy in different settings was also reviewed.

\section{Rationale for yttrium-90 TARE}

TARE is a form of brachytherapy in which microspheres loaded with yttrium-90 $\left({ }^{90} \mathrm{Y}\right)$ are injected into the hepatic arteries; ${ }^{22}$ it provides selective internal radiation of liver tumors owing to their preferential arterial blood supply. The rationale of TARE (also called "selective internal radiation therapy" or "SIRT") is to inject very small embolic particles (embolization) as the vehicle of a radiation source via fluoroscopic guidance which allows strict control of the procedure.

TARE is similar to TACE as regards the technical aspects of the procedure, since both require selective or superselective catheterization of the tumor-feeding vessels, but they differ significantly in their mechanisms of action. In TACE, the use of bland embolic particles, 3-10 times larger than those used in TARE (100 to 500 micron versus approximately 25-35 micron in diameter) has been demonstrated to occlude medium to large arteries with the aim of producing ischemia and eventually exposing the tumor cells to high concentrations of the drug (carried in lipiodol or drug-eluting beads), potentially enhancing tumor cell death. ${ }^{23}$ On the other hand, ${ }^{90}$ Y-microspheres have the aim of producing tumor necrosis by delivering a tumoricidal dose of radiation directly to the tumor nodules sparing the non-tumoral liver with little or no embolic effect on the vessels. ${ }^{24}$ Yttrium-90 is a pure beta emitter with a short half-life (2.67 days) and minor tissue penetration (mean $2.5 \mathrm{~mm}$, maximum $11 \mathrm{~mm}) .^{25}$

There are two commercially available microspheres loaded with ${ }^{90} \mathrm{Y}$, one made of resin (SIR-Spheres ${ }^{\circledR}$, Sirtex Medical, Sidney, NSW, Australia) and another made of glass (TheraSpheres ${ }^{\circledR}$, MDS Nordion, Toronto, Ont, Canada). The differences include the amount of activity contained in each microsphere and the number of microspheres injected in a single treatment ( $<5$ million to $10-30$ million for glass and resin microspheres, respectively). However, they are similar in efficacy, toxicity, and clinical outcome. The differences are summarized in Table 1.

Current evidence suggests that the primary method of action of both resin and glass microspheres is the same and is due to a localized radiotherapeutic effect (brachytherapy) rather than microvascular embolization and tumor ischemia. ${ }^{26-28}$

The dose of radiation absorbed depends on the distribution of the microspheres, which mainly results from hemodynamic arterial hepatic and tumor vascularization. In this way, we can expose tumors to a higher radiation dose than with external beam radiation therapy.

As is well known, HCC is a radiosensitive tumor; ${ }^{29}$ but external beam radiation therapy is not widely used due to severe liver toxicity, with a dose absorbed by the liver tissue of greater than $35 \mathrm{~Gy}^{30,31}$ However, by lowering the dose in 
Table I Characteristics of commercially available ${ }^{90} Y$-microspheres for TARE

\begin{tabular}{|c|c|c|}
\hline & SIR-Spheres $^{\text {a }}$ & TheraSphere $^{\mathrm{b}}$ \\
\hline Isotope ${ }^{90} \mathrm{Y}$ & $\begin{array}{l}\text { Attached to the } \\
\text { surface }\end{array}$ & $\begin{array}{l}\text { Incorporated into } \\
\text { the glass matrix }\end{array}$ \\
\hline Half-life (h) & 64.1 & 64.1 \\
\hline Microsphere material & Resin & Glass \\
\hline Microsphere diameter $(\mu \mathrm{m})$ & $20-60$ & $20-30$ \\
\hline Average size $(\mu \mathrm{m})$ & 32.5 & 25 \\
\hline $\begin{array}{l}\text { Approximate activity } \\
\text { per microsphere }(\mathrm{Bq})\end{array}$ & 50 & 2,500 \\
\hline $\begin{array}{l}\text { Number of microspheres } \\
\text { per } 3 \mathrm{GBq}\end{array}$ & $40 \times 10^{6}-80 \times 10^{6}$ & $1.2 \times 10^{6}$ \\
\hline Specific gravity $(\mathrm{g} / \mathrm{mL})$ & 1.6 & 3.6 \\
\hline $\begin{array}{l}\text { Activity per commercially } \\
\text { available vial }(\mathrm{GBq})\end{array}$ & 3 (can be divided) & $3,5,7,10,15,20$ \\
\hline Activity calculation & $\begin{array}{l}\text { Compartmental MIRD } \\
\text { macrodosimetry } \\
\text { or empirical formula } \\
\text { based on liver volume } \\
\text { and tumor volume }\end{array}$ & $\begin{array}{l}\text { Non- } \\
\text { compartmental } \\
\text { MIRD } \\
\text { macrodosimetry }\end{array}$ \\
\hline $\begin{array}{l}\text { Estimated dose to the } \\
\text { central vein area (Gy) in the } \\
\text { Monte Carlo simulation }{ }^{c}\end{array}$ & 59 & 58 \\
\hline Embolic effect & Moderate & Mild \\
\hline Contrast agent injection & During infusion & None \\
\hline Indication & $\begin{array}{l}\text { USA (FDA PMA): } \\
\text { Colorectal liver } \\
\text { metastases }\end{array}$ & $\begin{array}{l}\text { USA (FDA HDE): } \\
\text { Hepatocellular } \\
\text { carcinoma }\end{array}$ \\
\hline
\end{tabular}

Notes: Data from Sangro et al. ${ }^{25}$ aSirtex Medical, North Sydney, Australia; ${ }^{\text {bBTG }}$ International Canada Inc., Ottawa, ON, Canada; 'Gulec SA, Sztejnberg ML, Siegel JA, Jevremovic T, Stabin M. Hepatic structural dosimetry in (90)Y microsphere treatment: a Monte Carlo modeling approach based on lobular microanatomy. J Nucl Med. 20I0;5I (2):30I-3 I0. (C) by the Society of Nuclear Medicine and Molecular Imaging, Inc. Abbreviations: ${ }^{90} \mathrm{Y}$, yttrium-90; TARE, transarterial radioembolization; MIRD, Medical Internal Radiation Dosimetry; FDA, Food and Drug Administration; PMA, premarket approval; HDE, Humanitarian Device Exemption.

order to spare the liver parenchyma, a tumoricidal effect on liver tumors is not obtained (an effective dose must exceed $70 \mathrm{~Gy}^{32,33}$ ) but, instead, there is a rebound effect resulting in new lesions.

In TARE, dosimetry planning, the administration and delivery of the radiation, modification of the dose on the basis of tumor and hepatic volume, and the knowledge required regarding radiation effects on tissue make this therapy a brachytherapy procedure as well.

\section{Technical aspects of TARE Pretreatment evaluation}

The specific technical aspects of the TARE procedure have recently been addressed by an International Working Group, ${ }^{34}$ and a detailed review of the methodological and technical aspects of the procedure was undertaken by Salem et al. ${ }^{35}$
An interdisciplinary team with members from interventional radiology, hepatology, medical, surgical and radiation oncology, transplant surgery, nuclear medicine, and medical physics is crucial in the selection process of suitable candidates for TARE.

Patients are selected according to the following criteria: 1) a confirmed diagnosis of unresectable HCC; 2) age $>18$ years; 3 ) Eastern Cooperative Oncology Group performance status $\leq 2 ; 4$ ) adequate hematologic parameters (granulocyte count $<1.5 \times 10^{9} / \mathrm{L}$, platelet count $>60 \times 10^{9} / \mathrm{L}$ ), renal function (serum creatinine level $<2.0 \mathrm{mg} / \mathrm{dL}$ ), and liver function (serum total bilirubin level $<2.0 \mathrm{mg} / \mathrm{dL}$ ); and 5) the ability to undergo angiography and selective visceral catheterization. The majority of patients have a Child-Pugh score $\leq 7$ even though a Child-Pugh score $>7$ is not an absolute contraindication. The exclusion criteria are as follows: 1) any other liver-directed therapy planned for cancer treatment; 2) uncorrectable flow to the gastrointestinal tract; 3) lung shunting $>20 \%$ (resin microspheres) or estimated radiation doses to the lungs $>30 \mathrm{~Gy}$ (with a single administration) or $50 \mathrm{~Gy}$ (with multiple administrations); and 4) significant extrahepatic disease.

The tumor volume should not exceed $50 \%$ of the total liver volume; a tumor volume $>70 \%$, even in patients with normal liver function, is a relative contraindication for TARE.

\section{Pretreatment angiography}

In candidates for TARE, pretreatment angiography is carried out in order to detect the vascular anatomy and the tumor feeding vessels.

Thorough knowledge of the arterial anatomy is mandatory both to drive the therapy to the target lesions and to occlude, if necessary, the aberrant vessels arising from the hepatic arteries feeding the non-target tissue ${ }^{36}$ in order to prevent severe complications. ${ }^{35,37,38}$ Evaluation of the flow to the gastrointestinal tract or to other extrahepatic sites is mandatory.

There is no consensus regarding the prophylactic embolization of the gastroduodenal artery and the right gastric artery; the latter generally arises from the left hepatic artery but it has also been seen to emerge from the common, proper, right hepatic branch as well as from the gastroduodenal artery. ${ }^{27,35,37,38}$

Depending on the anatomical location of these vessels and on the distal catheterization achieved for the infusion, coil embolization should be performed to reduce the risk of hepatofugal reflux of the microspheres. The cystic artery, supraduodenal, retroduodenal, falciform, accessory left 

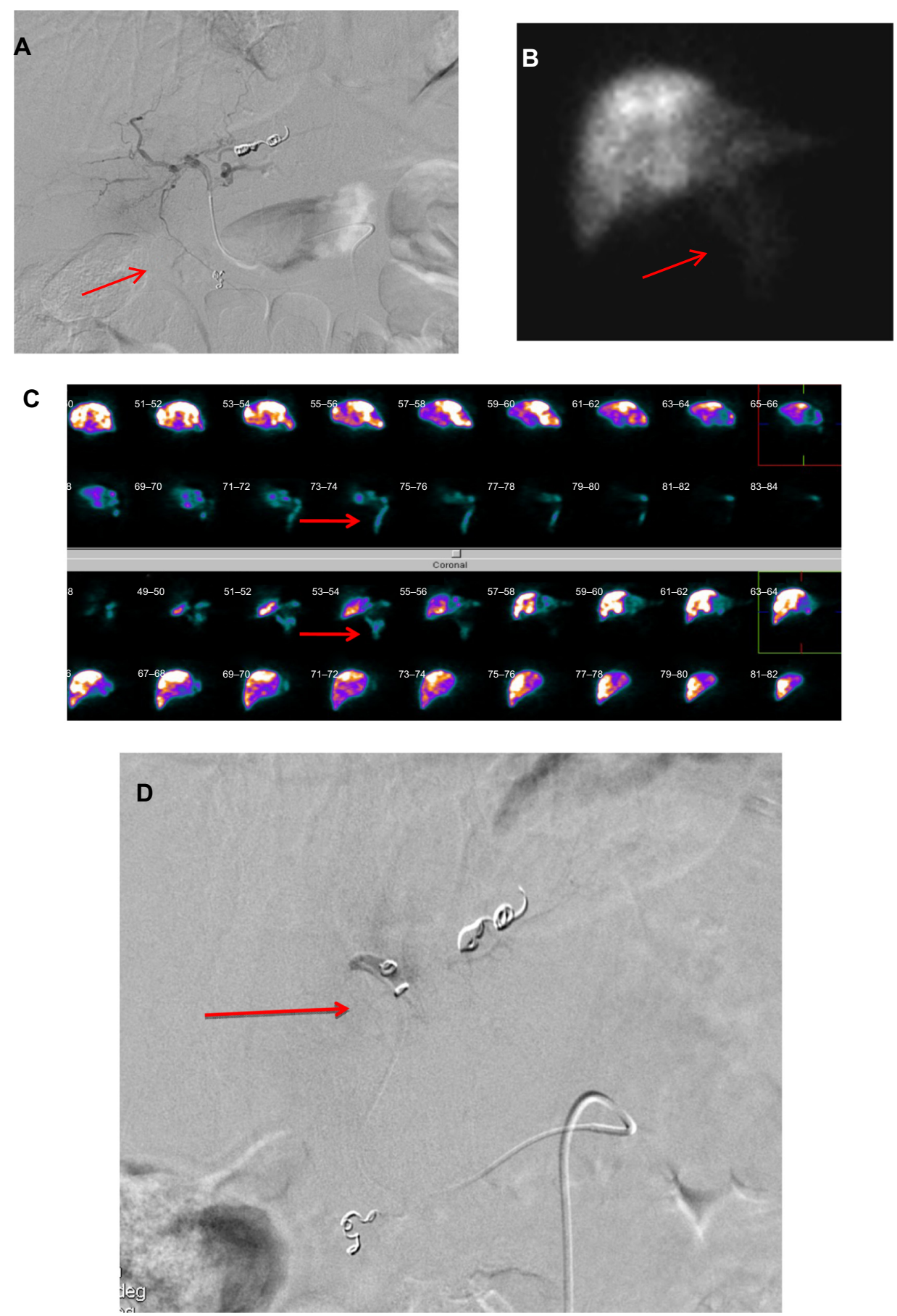

Figure I (A-D) The pretreatment angiogram.

Notes: (A) The hepatofugal flow through a small falciform artery (arrow). (B) The ${ }^{99 m}$ Tc-MAA and (C) the SPECT images confirmed the extrahepatic distribution of the microspheres (arrows). (D) The falciform artery was superselectively catheterized and embolized with coils (arrow).

Abbreviations: ${ }^{99 \mathrm{~m} T \mathrm{Tc}-M A A}$, ${ }^{99 \mathrm{~m} T c}$ labeled macroaggregated albumin; SPECT, single photon emission computed tomography.

gastric, and right and left inferior phrenic arteries should be located; they can all be embolized if necessary (Figure 1A-D; Figure 2A and B).

Pretreatment angiographic study is also useful in case it is necessary to alter the vascular anatomy in order to optimize the ${ }^{90} \mathrm{Y}$ infusion, as redistribution of the hepatic flow may be necessary in some cases. This is accomplished by the prophylactic embolization of a main vessel, for example, the left hepatic artery arising from the left gastric artery or a middle hepatic artery in order to convert the vascular bed for standard or whole lobe treatment, which is particularly useful in bilobar disease. 


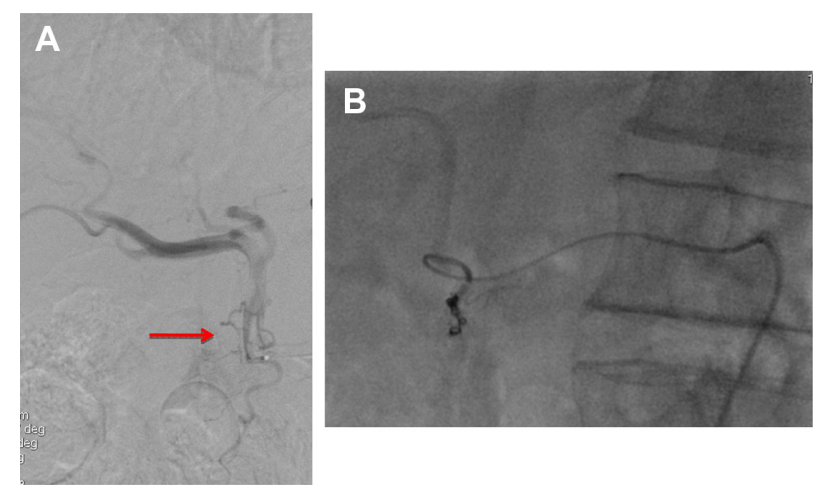

Figure 2 (A and $\mathbf{B})$ The pretreatment angiogram.

Notes: (A) This shows a very thin retroduodenal hepatic artery (arrow). (B) Superselective catheterization of the retroduodenal artery and embolization with microcoils.

\section{${ }^{99 m}$ Tc labeled macroaggregated albumin scintigraphy}

One of the most important complications related to TARE is the possible deposition of microspheres in extrahepatic sites, in particular in the lungs due to hepato-pulmonary shunts. Lung shunt evaluation is necessary to calculate the dose absorbed by the lungs which can represent a limitation of the ${ }^{90} \mathrm{Y}$ activity.

At the end of the pretreatment angiography, after vessel embolization if needed, $150-200 \mathrm{MBq}$ of ${ }^{99 \mathrm{~m}} \mathrm{Tc}$ labeled macroaggregated albumin ( $\left.{ }^{99 \mathrm{~m}} \mathrm{Tc}-\mathrm{MAA}\right)$ are intra-arterially administered into the arterial branch selected for the treatment. The MAA particles are considered to be a surrogate of the microspheres and can be used to simulate the distribution of microspheres to the liver, lungs, and possibly extrahepatic abdominal organs. Antero-posterior planar or whole body scintigraphy is performed to evaluate the lung shunt fraction while single photon emission computed tomography (SPECT) images are acquired to visualize the $3 \mathrm{D}$ distribution of the microspheres inside the tumor and the normal liver, as well as to assess the presence of extrahepatic localizations. ${ }^{39}$

When prophylactic embolization is required, it should be carried out at the time of ${ }^{99 \mathrm{~m}} \mathrm{Tc}-\mathrm{MAA}$ assessment in order to avoid the extrahepatic deposition of microspheres.

Furthermore, since these vessels can revascularize quickly, the embolization should be performed close to the TARE time and a control arteriography is required before the ${ }^{90} \mathrm{Y}$ infusion to ensure that revascularization has not occurred.

Scintigraphy is usually performed within one hour of the injection of ${ }^{99 \mathrm{~m}} \mathrm{Tc}-\mathrm{MAA}$ to avoid redistribution of free technetium and MAA particles, causing false-positive extrahepatic findings. Thyroid and stomach uptakes can be seen in ${ }^{99 m}$ Tc-MAA images, and may be confused with pathological uptake or extrahepatic deposition due to hepatogastric shunts. The lung shunt fraction (LSF) is then obtained by planar ${ }^{99 \mathrm{~m}} \mathrm{Tc}-\mathrm{MAA}$ images as follows:

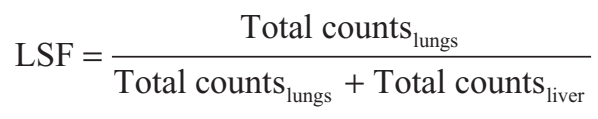

where total counts lungs is the geometric mean of the total counts in a region of interest positioned on the lungs in the anterior and posterior views of the ${ }^{99 \mathrm{~m} T c-M A A}$ scan, and total counts liver is the geometric mean of the total counts in a region of interest positioned on the liver in the anterior and posterior views of the ${ }^{99 \mathrm{~m}} \mathrm{Tc}-\mathrm{MAA}$ scan.

The dose to the lungs, due to the shunt, is:

$$
\mathrm{D}(\mathrm{Gy})_{\text {lungs }}=\frac{\mathrm{A}(\mathrm{GBq})_{\text {injected }} * \mathrm{LSF} * 50}{\mathrm{M}(\mathrm{Kg})_{\text {lungs }}}
$$

$\mathrm{A}(\mathrm{GBq})$ is the ${ }^{90} \mathrm{Y}$ injected activity, $\mathrm{D}(\mathrm{Gy})$ is the nominal dose to the lung and $\mathrm{M}(\mathrm{Kg})$ is the lung mass. The 50 is a constant which depends on the ${ }^{90} \mathrm{Y}$ physical characteristics.

\section{Dosimetry}

As in all other radiotherapy treatments, personalized treatment planning is desirable for TARE; liver and tumor volumes should be measured in order to deliver a curative therapeutic dose to the tumor while keeping the dose to normal tissues as low as possible..$^{40}$ In this treatment, it is necessary to know the distribution of the active microspheres in the tumor and, more generally, to the volume treated.

Image fusion of the morphologic and functional datasets allows the delineation of territories for volume evaluation, which are vascularized by the branch arteries selected for ${ }^{90} \mathrm{Y}$ microsphere infusion, and the differentiation between active tumoral tissue and necrotic tissue.

The objective of an optimal treatment is to deliver a low-radiation dose to normal treated volumes and a curative dose to tumors. An excessive dose to the normal liver is a severe complication which could induce radiation hepatitis and liver failure. The absorbed normal liver dose should be kept lower than 40 Gy to minimize the risk of liver failure, especially in patients with compromised liver function..$^{41}$ The radiation dose is strictly related to the injected activity and to the distribution of the microspheres in the different tissues. The calculation of the required activity personalized for each treatment is the crucial dosimetric point of this therapy and its optimization is often unreachable. 
For these reasons, the majority of TARE treatments are performed calculating the injected activity based on empiric formulas suggested by the manufacturers instead of following scrupulous dosimetric formalism. In the following paragraphs, the standard methods for activity assessment are briefly described for both glass and resin microspheres.

\section{Glass microspheres}

The activity determination for glass microspheres proposed by the manufacturer (TheraSphere ${ }^{90} \mathrm{Y}$ Glass Microspheres Users Manual, MDS Nordion, Ottawa, ON, Canada) is based on a nominal target dose (80-150 Gy) and the patient's treated mass (M) which is determined from the computed tomography (CT) data and assumes the uniform distribution of the microspheres throughout the treated volume:

$$
\mathrm{A}(\mathrm{GBq})_{\text {glass }}=\frac{\mathrm{D}(\mathrm{Gy}) * \mathrm{M}(\mathrm{kg})}{50}
$$

The lung dose should be kept to less than 30 Gy for a single injection and less than 50 Gy as a cumulative dose for multiple injections. ${ }^{42}$

Using this formula, the dose delivered to the tumor is not known; however, going on the assumption that tumors have a higher vascularity as compared to the normal parenchyma, it is reasonable to predict that the prescribed dose is at least that which is absorbed by the tumor in order to prevent liver fibrosis.

\section{Resin microspheres}

Two methods are proposed by Sirtex to determine the activity of the ${ }^{90} \mathrm{Y}$ to be injected: the empiric method and the Body Surface Area (BSA) method. ${ }^{43}$

The empiric method suggests a standard amount of activity based on tumor involvement only, considering three varying degrees of tumor involvement:

Tumors $\leq 25 \%$ of the total mass of the liver as determined by a CT scan $=2$ GBq whole-liver delivery

Tumors $\geq 25 \%$ but $\leq 50 \%$ of liver mass as determined by a

CT scan $=2.5 \mathrm{GBq}$ whole-liver delivery

Tumors $\geq 50 \%$ of liver mass as determined by a CT scan $=3 \mathrm{GBq}$ for whole liver delivery

This method is not recommended by the scientific community. ${ }^{44}$

The BSA method is a variant of the empiric method which calculates the injected activity taking into account the patient's BSA and the fraction of liver volume involved by the tumor:

$$
\mathrm{A}(\mathrm{GBq})=(\mathrm{BSA}-0.2)+\frac{\mathrm{V}_{\text {tumor }}}{\mathrm{V}_{\text {tumor }}+\mathrm{V}_{\text {normal liver }}}
$$

where $\operatorname{BSA}\left(\mathrm{m}^{2}\right)=0.20247 *$ height $(\mathrm{m})^{0.725 *}$ weight $(\mathrm{kg})^{0.425}$. The BSA formula is considered safe for patients with compromised liver function or for particularly small patients. A reduction of the amount of activity of up to $20 \%$ is recommended for lung shunts greater than $15 \%$.

\section{Dosimetric approach}

None of the methods presented above can be considered a real dosimetric approach for the treatment because the distribution of the ${ }^{90} \mathrm{Y}$ microspheres and the uptake ratio between the tumor and the normal parenchyma are never considered, preventing any accurate dosimetric evaluation.

A dosimetric approach based on Medical Internal Radiation Dosimetry (MIRD) formalism was proposed by Sirtex as a partition model, and has been formalized with MIRD equations by Gulec et al. ${ }^{45}$ The MIRD formalism is based on the determination of the fraction of activity (fractional uptake) which is trapped by the tumor, normal liver, and lungs when the masses of each compartment are calculated using CT images. The fractional uptake is measured by ${ }^{99 \mathrm{~m}}$ Tc-MAA SPECT images, calculating the tumor-to-liver ratio and the lung shunt fraction. Since the dose to the normal parenchyma is the most important limiting factor, the activity administered can be calculated as the activity which delivers the selected nominal dose to the liver, namely:

$$
\mathrm{A}(\mathrm{GBq})_{\text {injected }}=\frac{\mathrm{D}(\mathrm{Gy})_{\text {liver }} * \mathrm{M}(\mathrm{Kg})_{\text {liver }}}{50}
$$

where $\mathrm{A}(\mathrm{GBq})$ is the ${ }^{90} \mathrm{Y}$ injected activity, $\mathrm{D}(\mathrm{Gy})$ is the nominal dose to the liver, and $\mathrm{M}(\mathrm{Kg})$ is the liver mass. The 50 is a constant which depends on the ${ }^{90} \mathrm{Y}$ physical characteristics.

Once the fraction of activity reaching each compartment/ tissue is measured, the corresponding dose absorbed is evaluated using the following formula:

$$
\mathrm{D}(\mathrm{Gy})_{\text {tissue }}=\frac{50 * \mathrm{~A}(\mathrm{GBq})_{\text {tissue }}}{\mathrm{M}(\mathrm{Kg})_{\text {tissue }}}
$$

Although the use of ${ }^{99 m}$ Tc-MAA particles allows predicting absorbed doses before ${ }^{90} \mathrm{Y}$ infusion, it is quite imprecise 
and could be affected by several serious limitations. In particular, the major limitations of this pretreatment dosimetry are the size and specific gravity of the ${ }^{99 \mathrm{~m}}$ Tc-MAA and ${ }^{90} \mathrm{Y}$ microspheres, the volume and velocity of injection, the reproducibility of the exact site of injection, and the hemodynamic conditions inside the tumor which can be considerably different between the ${ }^{99 \mathrm{~m}} \mathrm{Tc}-\mathrm{MAA}$ and the ${ }^{90} \mathrm{Y}$ treatment procedures. Furthermore, assuming uniform distribution of the microspheres, the average absorbed dose measures the mean dose inside a tumor and not the actual dose which, on the contrary, is strongly dependent on the heterogeneous vessel density.

However, in patients affected by HCC, tumor response, as assessed by the criteria, was associated with higher mean absorbed doses for both resin ${ }^{46}$ and glass microspheres. ${ }^{40}$

Furthermore, the intrinsic differences between the two types of microspheres, in particular, their different numbers and specific activity, are responsible for the different distribution of the microspheres inside tissues which are more uniform for resin than for glass microspheres. Consequently, published data regarding dosimetry report higher values for tumor response dose for glass microspheres than for resin microspheres. ${ }^{46,47}$

\section{TARE procedure}

The procedure is carried out according to previously published guidelines, ${ }^{34,35,48}$ based on the experience of more than $900{ }^{90} \mathrm{Y}$ infusions performed over a 5-year period.

The shielding device for administering ${ }^{90} \mathrm{Y}$ resin or glass microspheres is designed to minimize radiation exposure to the clinical team, and to optimize the flexibility and control during administration. The predefined activity is injected into the tumor-bearing lobe, or one or more segments, as required. At the end of the procedure, a medical physicist checks the angiographic room and the materials used to ensure that proper protocols have been followed and to reduce accidental radiation exposure.

\section{Post-treatment assessment}

Clinical, laboratory, and radiologic follow-ups must be carried out to monitor both the tumor response to treatment and to identify any toxicity. Liver function tests, a complete blood count, tumor marker analysis, and cross-sectional imaging (CT and/or magnetic resonance imaging [MR]) should be carried out at 1 month post-procedure and then every 3 months; in the presence of residual viable disease, a second treatment should be programmed not earlier than 30-60 days after the first one.

\section{Imaging after TARE}

Imaging after TARE shows a change in both the appearance of the tumor and the surrounding liver. The first scan performed at 1 month after the procedure may not be representative of the extent of the necrosis; in fact, the effect of the radiation source can also be manifest at imaging carried out after 30 days.

A common early feature is the appearance of rim enhancement surrounding the lesion; it is the sign of a fibrotic capsule and it is fundamental not to erroneously consider it as a residual tumor. ${ }^{49}$

CT may limit the capability of documenting the tumor necrosis, but changes in the size of the lesions, alterations in vascularity and enhancement, and the appearance of new intra or extrahepatic lesions are well defined with this technique.

In a period ranging from 8 to 12 weeks after TARE, there is noticeable tumor shrinkage which can be measured, using CT or MR imaging, to assess tumor response in the index lesions with the modified Response Evaluation Criteria in Solid Tumors (mRECIST) ${ }^{50}$ or the European Association for the Study of Liver Disease (EASL) criteria, the former measuring the diameter and the latter the area of the enhancing tumor ${ }^{51}$ (Figure 3A-G).

If MR imaging is used, diffusion-weighted imaging and gadolinium-ethoxybenzyl-diethylenetriamine pentaacetic acid imaging better identify necrosis and cell death ${ }^{52}$ earlier (6-8 weeks post-procedure in some cases), better than CT does. ${ }^{48,53}$

After a period of 8-12 weeks, the parenchyma becomes atrophic as a consequence of hepatic fibrosis and capsular retraction of the treated lobe (Figure 4A-F). This finding is more evident after lobar procedures rather than after a segmental or subsegmental approach. The atrophy of the treated lobe induces a compensatory hypertrophy of the contralateral lobe as seen after a lobectomy (Figure 4A-F).

Another common feature is the appearance of transient perfusion abnormalities in the treated area, which should be differentiated from residual or recurrent tumors (Figure 4A-F). Furthermore, transient hypoattenuating perivascular edema near the hepatic and portal veins can also be observed on a CT scan.

Progression is defined as the appearance of new lesions observed in intra- and extrahepatic sites. The identification of early progressors is very important since the adjunctive role of systemic agents (such as sorafenib) is likely to be a key component in improving long-term outcomes. ${ }^{54}$ 

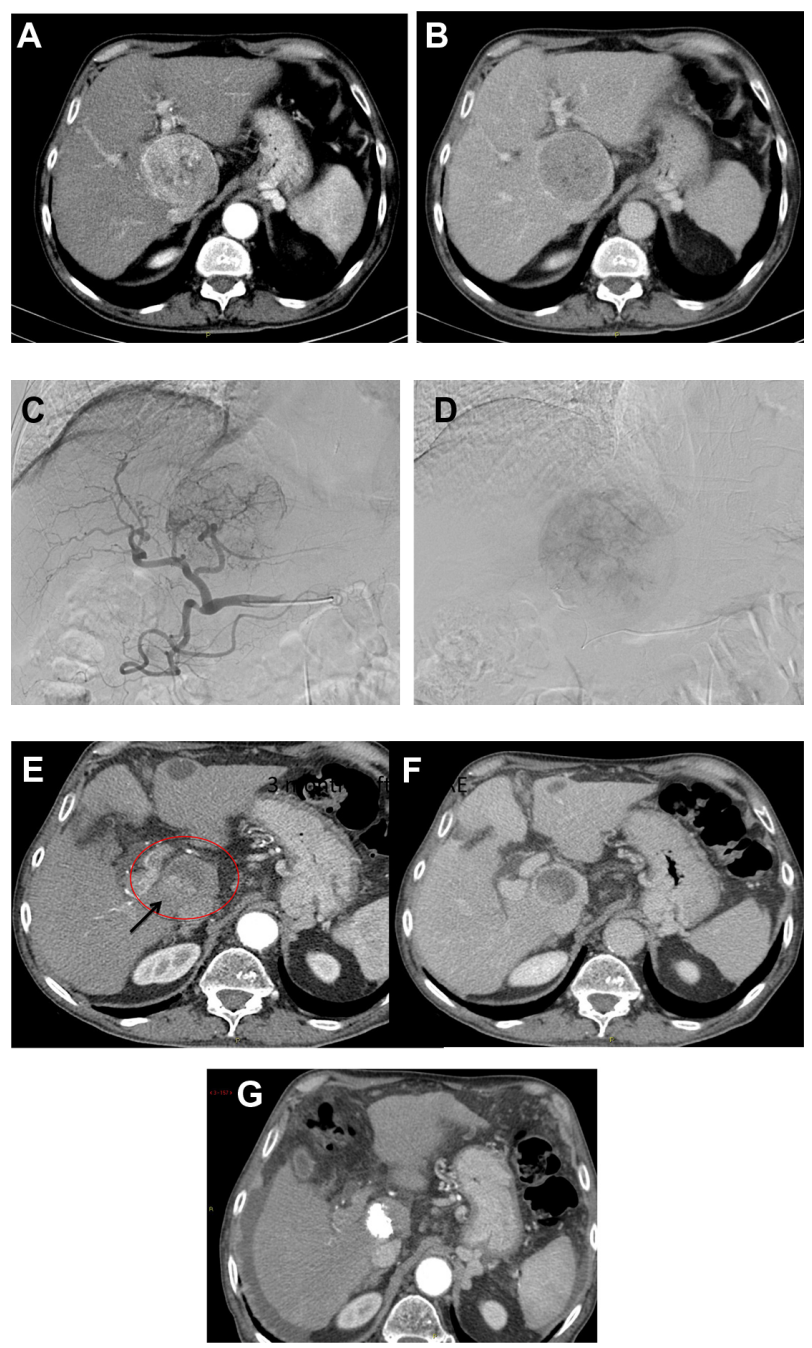

Figure 3 (A-G) Large HCC of segment I as shown on CT.

Notes: (A) During the arterial and (B) the portal-venous phase, further confirmed at (C) angiography. (D) Superselective TARE treatment. (E) At a 6-month follow-up, showing the significant volume decrease of the target lesion (circle in E) best seen in the portal-venous phase (F) with the appearance of a minimally viable tumor (arrow) further treated with conventional can also be applied as a second-line treatment in patients progressing TACE with a complete uptake of Lipiodol (G).

Abbreviations: HCC, hepatocellular carcinoma; CT, computed tomography; TARE, transarterial radioembolization; TACE, transarterial chemoembolization.

\section{Safety, tolerability, and toxicity}

The safety ofTARE for HCC has been well documented in the literature. ${ }^{55-58}$ In fact, this therapy has excellent tolerability and a low incidence of complications which result from the irradiation of non-target tissues, including the non-tumor liver compartment. The incidence of complications can be further reduced by patient selection and by rigorous pretreatment assessment, including dosimetry models and the thoroughness of the technique applied. ${ }^{49}$

The most common side effect is post-embolization syndrome; its incidence ranges from $20 \%$ to $55 \% .{ }^{59,60}$ The degree of symptoms is reported to be less severe than compared to $\mathrm{TACE}^{27}$ and, after TARE, they are generally transient.
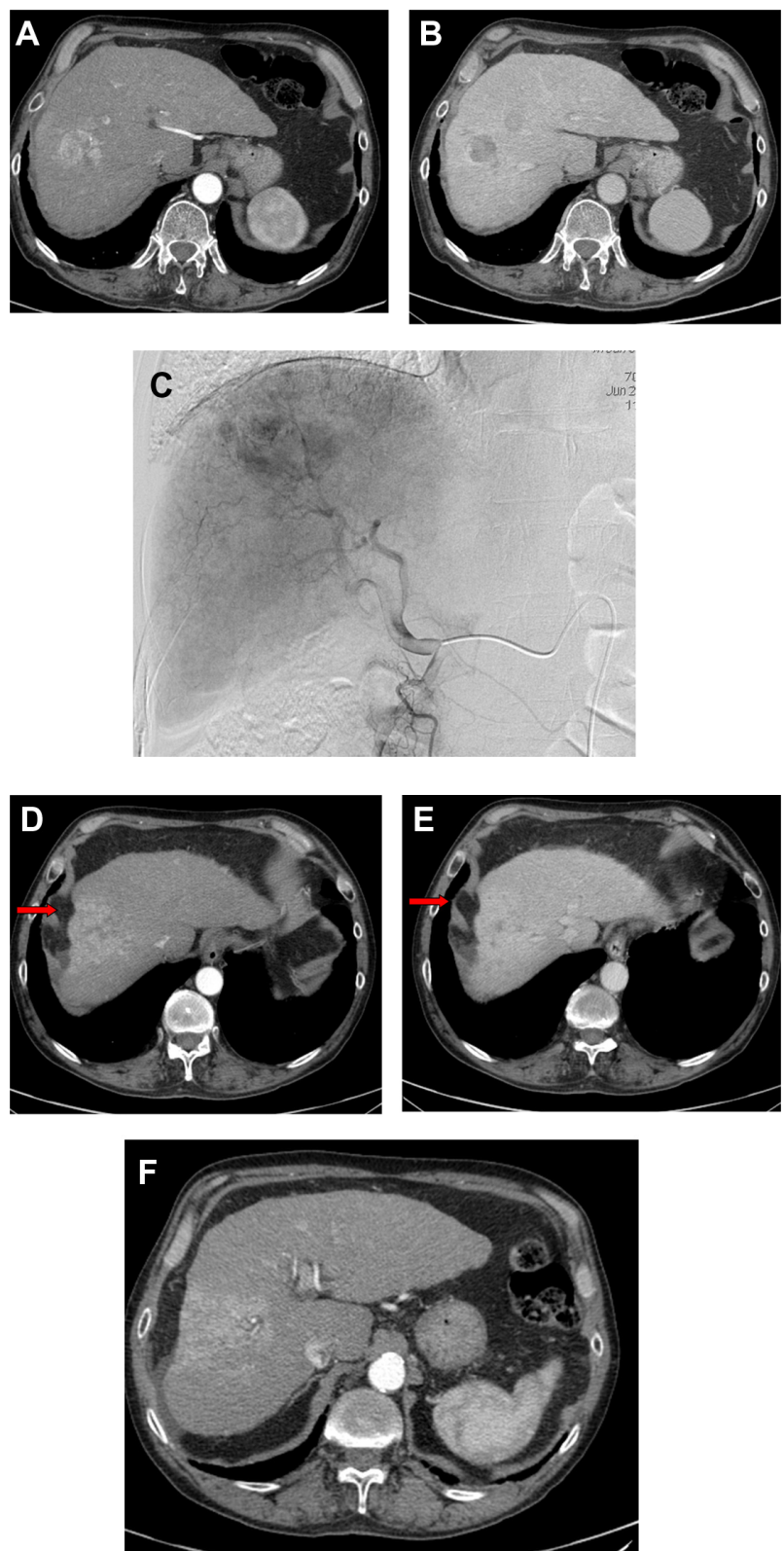

Figure 4 (A-F) Bilobar HCC of the right hepatic lobe (V-VIII segments). Notes: (A) The pretreatment CT shows hypervascularization of the larger lesion in the arterial phase and (B) the hypoattenuation of both nodules in the portalvenous phase. (C) The pretreatment angiogram confirms the large HCC nodule of the dome of the liver. CT study performed 8 months after treatment shows the complete devascularization of the lesions. Note the capsular retraction of the treated segment as a consequence of hepatic fibrosis (arrows) and the transient perfusion abnormalities in the treated area, persistent in both (D) the arterial and (E) the portal-venous phase which is, however, not a recurrent tumor. (F) Of note, the compensatory hypertrophy of the left lobe.

Abbreviations: HCC, hepatocellular carcinoma; CT, computed tomography.

In large series, ${ }^{10,61,62}$ the main clinical symptoms reported are fatigue $(54 \%-61 \%)$, mild-to-moderate abdominal pain $(23 \%-56 \%)$, nausea and vomiting $(20 \%-32 \%)$, and fever $(3 \%-12 \%)$ usually lasting a few hours. The majority of these symptoms resolve spontaneously. 


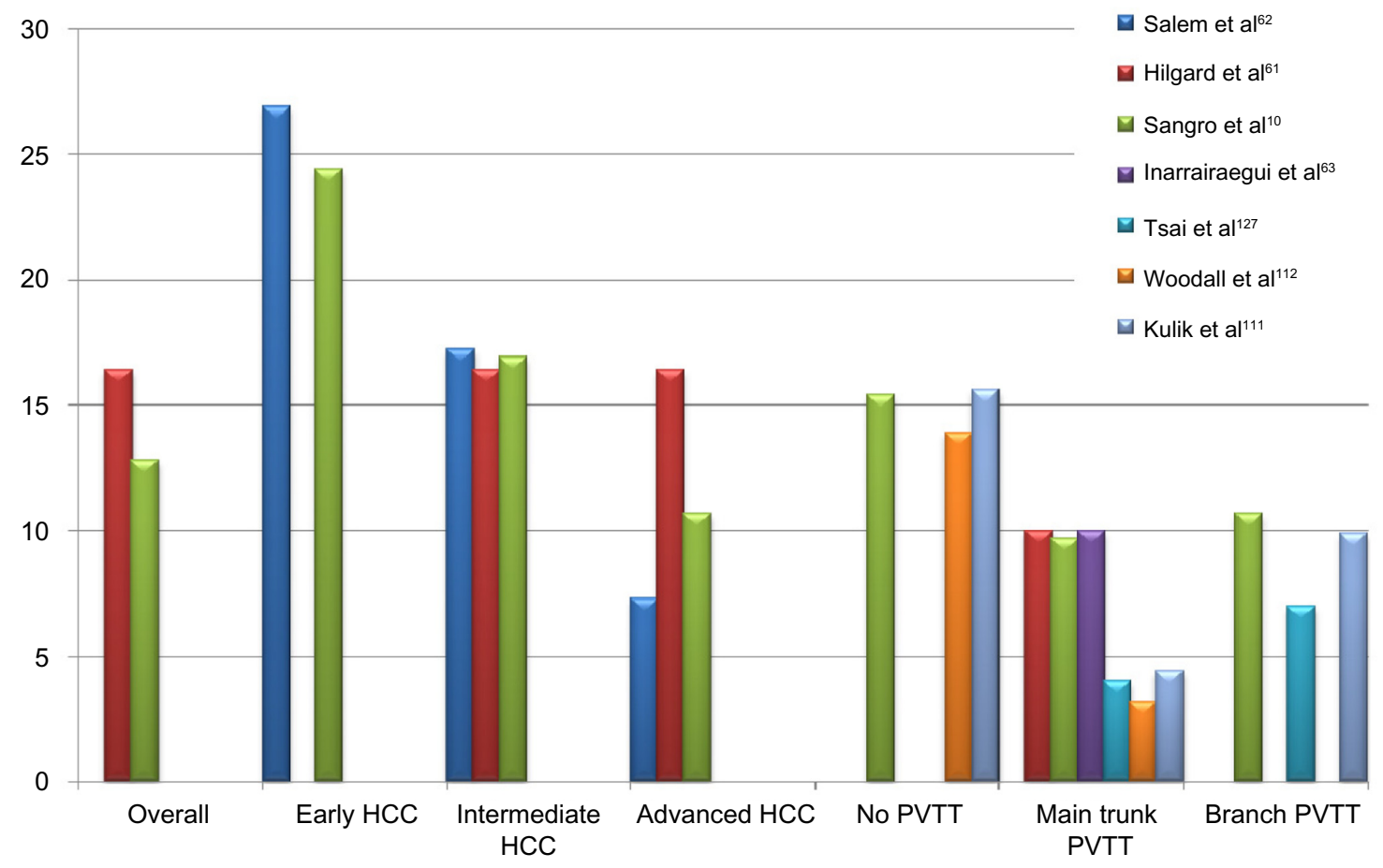

Figure 5 Graph of median survival (in months) according to BCLC stages and PVTT reported by the different series. Abbreviations: HCC, hepatocellular carcinoma; BCLC, Barcelona Clinic Liver Cancer; PVTT, portal vein tumor thrombosis.

Moreover, TARE is also a safe procedure in patients with portal vein tumor thrombosis (PVTT) ${ }^{63,64}$ in whom TACE could be dangerous, leading to a higher risk of complications, such as abscess or decompensation of the cirrhosis. ${ }^{65}$

A small series from Gaba et $\mathrm{l}^{66}$ reports the safety of TARE in asymptomatic patients with lobar or segmental biliary tract obstruction but normal bilirubin. The incidence of biliary sequelae after TARE is reported to be $<10 \%$; radiation-induced cholangitis is a very rare event. The lack of significant ischemia has been reported in animal models. ${ }^{24}$ According to Atassi et al, ${ }^{67}$ less than $2 \%$ of patients required drainage of bilomas, treatment of abscesses, and cholecystectomies. However, the treatment is not recommended in patients with main biliary duct obstruction or stenting.

Mild to moderate lymphopenia may be experienced in patients after TARE, but an association with increased susceptibility to infections has not been demonstrated. ${ }^{55}$ Other side effects to be expected after treatment are a transient elevation in liver function tests, specifically in alkaline phosphatase, bilirubin, and alanine transferase levels. ${ }^{41,68}$

TARE can lead to severe toxic effects as a result of the non-targeted distribution of ${ }^{90} \mathrm{Y}$-microspheres, such as radiation-induced gastroduodenal ulcerations and pancreatitis,${ }^{69-71}$ portal hypertension, radiation cholecystitis ${ }^{55}$ pneumonitis ${ }^{42}$ bile duct injuries, ${ }^{49}$ radioembolization-induced liver disease (REILD) and, most importantly in HCC cirrhotic patients, liver toxicity.

REILD is defined by the occurrence of jaundice, mild ascites in the absence of tumor progression or bile duct obstruction, a marked increase in bilirubin and alkaline phosphatase, and no change in transaminase levels and liver function tests, the latter ranging from $15 \%$ to $20 \% .{ }^{41}$ REILD is described as a form of sinusoidal obstruction syndrome which usually occurs $4-8$ weeks after TARE. ${ }^{41}$ It is difficult to establish the actual incidence of this complication (Table 2), mainly due to the fact that the majority of published series report the change in laboratory tests over different periods of time (from 30 days to the entire follow-up period). Nevertheless, the two largest series ever published ${ }^{10,61}$ report grade 3 or higher classification according to the National Cancer Institute Common Toxicity Criteria Adverse Events (CTCAE) bilirubin levels (a hallmark of REILD) within 3 months after treatment in $14 \%$ of patients treated with glass microspheres (mostly in a lobar fashion) and in $6 \%$ of patients treated with resin microspheres (almost half of them treated in a bilobar fashion) (CTCAE Version 3.0)..$^{72}$ These data suggest that the increased bilirubin levels reflect some kind of REILD even though a causal relationship with the treatment could not be demonstrated in controlled prospective trials in which the adverse events are recorded and compared to those occurring in the control arm. This hypothesis is supported by the fact 
Table 2 Liver-related side effects after TARE reported in the largest series

\begin{tabular}{|c|c|c|c|c|c|c|}
\hline Study (year) & No of patients & $\begin{array}{l}\text { Interval (days) } \\
\text { post-treatment }\end{array}$ & $\begin{array}{l}\text { Ascites } \\
\text { (\%) }\end{array}$ & $\begin{array}{l}\text { Total bilirubin } \\
\text { grade }>3(\%)\end{array}$ & $\begin{array}{l}\text { Transaminases } \\
\text { grade }>\mathbf{3}(\%)\end{array}$ & Other liver-related SAEs \\
\hline Lau et $\mathrm{a}^{57}$ (1998) & 71 & NR & NR & NR & & $4 \%$ liver failure (not RILD) \\
\hline Dancey et $\mathrm{al}^{76}(2000)$ & 22 & NR & NR & $22^{\mathrm{a}}$ & $22^{\mathrm{a}}$ & Two potential treatment-related deaths \\
\hline Geschwind et al $\mathrm{a}^{77}$ (2004) & 80 & 0-90 & $7^{\mathrm{a}}$ & $16^{a}$ & $6^{a}$ & One treatment-related death \\
\hline Carr et $\mathrm{al}^{55}(2004)$ & 65 & $0-180$ & 12 & $38^{\mathrm{a}}$ & & \\
\hline Salem et al ${ }^{59}(2005)$ & 43 & 0-90 & 7 & $14^{b}$ & $5^{b}$ & \\
\hline Goin et $\mathrm{al}^{123}(2005)$ & 121 & $0->90$ & NR & NR & & $5 \%$ treatment-related deaths \\
\hline Sangro et al ${ }^{126}(2006)$ & 24 & 0-90 & NR & $12^{\mathrm{b}}$ & & Two treatment-related deaths \\
\hline \multirow[t]{2}{*}{ Kulik et al"' (2008) } & 82 (cirrhotic) & $0-180$ & $18^{\mathrm{b}}$ & $40^{\mathrm{b}}$ & & $4 \%$ encephalopathy CTC grade 3 \\
\hline & 26 (non-cirrhotic) & & $4^{\mathrm{b}}$ & $4^{b}$ & & $0 \%$ encephalopathy \\
\hline Hilgard et al ${ }^{61}(2010)$ & 108 & $0->90$ & $0^{\mathrm{b}}$ & $23^{\mathrm{b}}$ & $0^{\mathrm{b}}$ & $3 \%$ encephalopathy CTC grade 3 \\
\hline Kooby et al ${ }^{122}(2010)$ & 27 & $0-30$ & NR & NR & & $22 \%$ hepatic dysfunction \\
\hline Salem et al ${ }^{62}(2010)$ & 291 & 0-90 & NR & $14^{\mathrm{b}}$ & $20^{\mathrm{b}}$ & \\
\hline Sangro et al ${ }^{10}(20 \mathrm{II})$ & 325 & $0-90$ & NR & $5^{\mathrm{b}}$ & $3^{\mathrm{b}}$ & \\
\hline
\end{tabular}

Notes: ${ }^{a}$ CTC ( $>3$ times the upper normal limit); $; 0$ bSWOG (>200\% increase from baseline). This Table was published in J Hepatol, 56(2), Sangro B, Iñarrairaegui M, Bilbao JI, Radioembolization for hepatocellular carcinoma, 464-473, @ Copyright Elsevier $2012 .^{25}$

Abbreviations: TARE, transarterial radioembolization; SAEs, serious adverse events; NR, not reported; RILD, radiation-induced liver disease; CTC, common terminology criteria; SWOG, Southwest Oncology Group.

that the increase in bilirubin levels is not associated with other changes in liver decompensation, such as decreased albumin levels or prothrombin activity. ${ }^{10}$ In fact, within 3 months after therapy, $19 \%$ of the patients experienced an increase in the CTCAE grade of albumin and $15 \%$ of patients an increase in international normalized ratio, relevant changes (grade 3 or higher) which were observed in only $0.8 \%$ and $1.8 \%$ of patients, respectively.

Pneumonitis is a rare event due to the mandatory quantification of pretreatment lung shunting. ${ }^{41,42}$ Monitoring of the development of pneumonitis is necessary if the lung shunt fraction is greater than $13 \%{ }^{42}$

Other events could be gastroduodenal ulcerations (less than $5 \%$ of patients) and pancreatitis (less than $1 \%$ of patients), due to the inadvertent reflux of microspheres in the gastrointestinal tract. These events can be avoided through prophylactic coil embolization of vessels to prevent the non-target deposition of microspheres, which is possible if a proper technique is used (ie, the slow and controlled injection of microspheres). ${ }^{41,69,71}$

In a retrospective analysis involving 325 patients conducted on the database of the European Network on Radioembolization with ${ }^{90} \mathrm{Y}$ resin microspheres study group, ${ }^{73}$ the clinical outcomes of the elderly as compared to younger patients were evaluated.

The authors reported that TARE was equally well tolerated in all cohorts and that the common procedure-related AEs were of mild-to-moderate intensity and of short duration.

Moreover, in the elderly cohort ( $\geq 75$ years), no AEs were of grades $\geq 3$. The difference in the occurrence of severe AEs was not statistically significant in the two cohorts. Gastro- intestinal ulceration was predominantly mild or moderately severe in both the younger and the elderly patients $(P=0.320)$; severe increases in total bilirubin (to grade $\geq 3$ ) at 3 months as compared to baseline were observed in $4.3 \%$ and $6.9 \%$ of the elderly and the younger populations, respectively $(P=0.432)$, and in $4.2 \%$ of the very elderly population. A greater number of elderly patients experienced hypoalbuminemia $(P=0.018)$ and elevated alanine transaminase $(P=0.015)$ at 3 months, although these changes were mild (grades 1-2).

Two considerations should be taken into account regarding the use of TARE in a cirrhotic liver. The altered microvascular pattern and the presence of anatomical arterioportal and arteriovenous shunts may change the radiation dose absorbed by both the tumor and the non-tumoral parenchyma, affecting the efficacy and the tolerability of the treatment as a consequence. On the other hand, cirrhotic patients have a reduced functional reserve, that is a reduced liver mass and liver blood flow, which could be further compromised by direct liver cell injury induced by TARE.

In the long-term, TARE has been shown to cause liver fibrosis, resulting in the "shrinkage" of the treated hepatic parenchyma and occasionally the appearance of portal hypertension, based on radiological findings; relevant clinical manifestations of portal hypertension are rare. ${ }^{74,75} \mathrm{~A}$ careful dose adjustment of ${ }^{90} \mathrm{Y}$ is therefore required to prevent nontarget parenchymal damage.

\section{Response, survival, and prognostic factors}

The benefits of ${ }^{90} \mathrm{Y}$ TARE in patients with HCC have been widely described. ${ }^{59,67,76-82}$ Data from the literature report a 
Table 3 Outcomes after TARE from recent studies

\begin{tabular}{|c|c|c|c|c|}
\hline Study (year) & No of patients & Response rate & Survival (months) & Prognostic factors \\
\hline \multirow[t]{2}{*}{ Carr et al $\mathrm{al}^{55}(2004)$} & 65 & OR $38 \%$ & Okuda I: 21 & \\
\hline & & & Okuda II: 10 & \\
\hline \multirow[t]{2}{*}{ Salem et $a^{59}(2005)$} & 43 & PR $47 \%$ & Okuda I: 24 & Main PVTT; AFP $>400 \mathrm{ng} / \mathrm{mL}$ \\
\hline & & & Okuda II: 13 & Tumor burden $>25 \%$ \\
\hline Sangro et al ${ }^{126}(2006)$ & 24 & PR 24\%; SD 64\% & 7 & \\
\hline \multirow[t]{2}{*}{ Young et al ${ }^{68}$ (2007) } & 41 & & Okuda I: 21.7 & \\
\hline & & & Okuda II: 14.2 & \\
\hline Kulik et al'"I (2008) & 71 & PR 42\%; SD 35\% & 15.5 & \\
\hline Salem et al ${ }^{48}(20 \mathrm{II})$ & 123 & RR $72 \%$ & 20.5 & Sex (female); Child-Pugh class; UNOS \\
\hline Sangro et al ${ }^{126}(2012)$ & 325 & & 12.8 & ECOG; nodules $>5$; INR $>1.2$; extrahepatic disease \\
\hline Mazzaferro et al ${ }^{83}(2013)$ & 52 & CR 9.6\%; OR $40.4 \%$ & 15 & Response; Child-Pugh class \\
\hline
\end{tabular}

Note: Reproduced from Kim YH, Kim do Y. Yttrium-90 radioembolization for hepatocellular carcinoma: what we know and what we need to know. Oncology. 20 I3;84 Suppl I:34-39, with permission from S. Karger AG, Basel. ${ }^{125}$

Abbreviations: TARE, transarterial radioembolization; OR, odds ratio; PR, partial response; PVTT, portal vein tumor thrombosis; AFP, alpha-fetoprotein; SD, stable disease; RR, response rate; UNOS, United Network of Organ Sharing; ECOG, European Cooperative Oncology Group; INR, international normalized ratio; CR, complete response.

response rate which varies among published studies, mainly due to the heterogeneous populations enrolled (Table 3 ). There was a $50 \%$ reduction in tumor volume in $19(26.7 \%)$ out of 71 patients after the first treatment of an initial experiment. ${ }^{82}$

In a German multicenter study ${ }^{61}$ carried out on 108 patients, complete response was obtained in two $(3 \%)$ patients, partial response in $23(37 \%)$ and stable disease in $33(53 \%)$ patients 3 months after treatment using the EASL criteria.

In a European prospective study involving 52 patients with a median follow-up of 36 months, Mazzaferro at al ${ }^{83}$ reported an objective response and a disease control rate of $40.4 \%$ and $78.8 \%$, respectively, according to the EASL response criteria. A complete response occurred in fie patients ( $9.6 \%$ of cases).

More recently, Weng et al ${ }^{84}$ reported data from 149 patients treated with TARE, establishing a new model for predicting survival in HCC patients 1 month afterTARE. This prognostic model differentiated the outcome of patients with different risk scores based on independent predictors of survival according to a multivariate proportional Hazards model; of these, the Choi et al ${ }^{85}$ criteria for tumor response at $\mathrm{CT}$ are included. The authors considered the greater precision of the Choi et al criteria, ${ }^{85}$ compared to RECIST (Response Evaluation Criteria in Solid Tumors) and mRECIST (modified RECIST), in the response evaluation by measuring not only tumor size but also the changes in tumor density (Hounsfield Units at CT).

\section{Clinical indications and potential roles according to tumor stages}

As has already been reported above, the use of TARE in HCC is mainly supported by data based on retrospective series and uncontrolled prospective studies (levels of evidence II-2 and II-3). $8,61,62,86$
The prospective SIRTACE study, ${ }^{87}$ a randomized multicenter pilot trial, has recently reported similar outcomes between TARE and TACE for intermediate-stage HCC. Furthermore, data coming from three large series, involving more than 700 patients, have provided a strong source of information regarding the overall survival, safety, and tolerability of TARE as compared to other treatment options, stratifying the population into subgroups according to BCLC stage. ${ }^{10,61,62}$

Figure 5 shows the graph of the median survival according to BCLC stage and PVTT reported by different series. Before 2008 and, in particular, before the publication of two large randomized trials ${ }^{12,21}$ which reported a benefit in terms of survival rate in patients with mixed intermediate and advanced stages who were treated with sorafenib, TARE was the therapeutic option in HCC patients at different stages which either progressed or relapsed after TACE or patients who were poor candidates for TACE due to the presence of PVTT or bulky tumors.

It is important to note that patients with segmental or subsegmental PVTT may be considered for TACE; ${ }^{88,89}$ on the other hand, the presence of nodules $\geq 10 \mathrm{~cm}$ in diameter should be considered a relative contraindication for TACE ${ }^{89}$

D'Avola et $\mathrm{al}^{90}$ showed that survival was significantly better in a cohort of patients treated with TARE as a firstline therapy than in the control group who were treated with conventional/experimental or no therapy. At this point, the evidence that TARE can prolong survival in patients not amenable to TACE has been reported in several studies. The range of survival was 9-16 months versus 7.9 months $^{76,82,61}$ in a similar group of patients in the SHARP (the Sorafenib Hepatocellular Carcinoma Assessment Randomized Protocol) trial. ${ }^{21}$ 


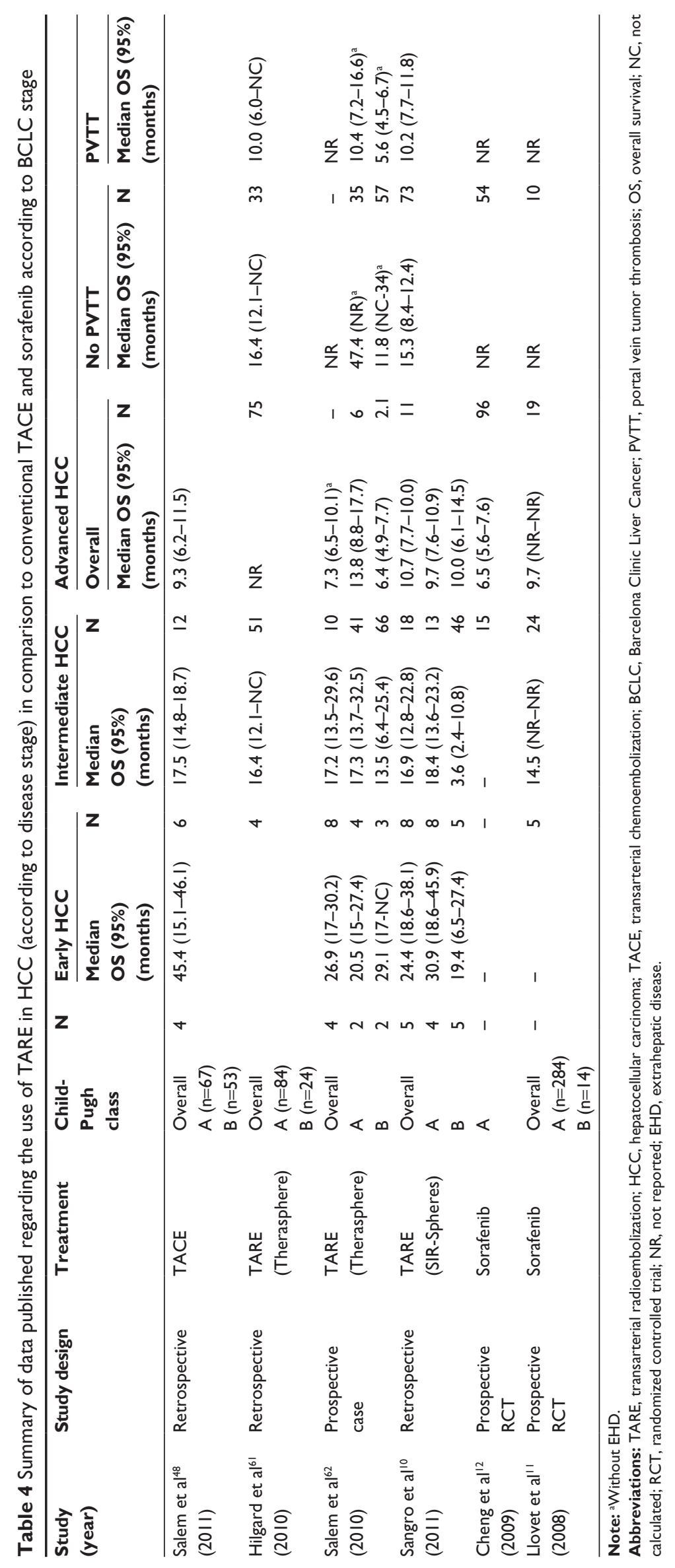


The data published regarding TARE in HCC patients (according to disease stage) in comparison to conventional TACE and sorafenib are summarized in Table 4.

In the intermediate stage HCC (BCLC-B), TACE is the first-line therapy for asymptomatic patients with multinodular unresectable HCC. ${ }^{8,91-93}$ Nevertheless, these data come from trials which enrolled a large number of patients in the early stage, and the TACE procedure was performed with very different modalities all over the world.

The majority of patients with intermediate-stage HCC who are treated with TARE as a first-line therapy are generally patients not suitable for TACE due to bulky disease with a single large nodule or more than five nodules in both lobes but with a normal performance status. These patients (BCLC-B stage) demonstrated a survival of $15.4-16.6$ months, ${ }^{10}$ not very different from the median OS of 15.6-17.4 months observed in patients treated with TACE. ${ }^{94-96}$ Survival was even better after TARE than after TACE in patients who were ideal candidates for TACE as reported by Sangro et a ${ }^{10}$ with a median OS of 22.8 months in patients with one to five nodules and 23.2 months for those with unilobar disease.

\section{TARE versus TACE in intermediate stage HCC}

Several authors have compared the outcomes following TARE and TACE in matched patient cohorts; Table 5 summarizes the largest and the most significant series reported in the literature.

The survival rate after TARE is promising in intermediatestage (BCLC-B) HCC with a median OS of 22.8 months (one to five nodules) and 23.2 months (unilobar disease). ${ }^{10}$ A cumulative meta-analysis ${ }^{8}$ positioned TACE as the firstline therapy for BCLC-B patients; the median survival rate exceeds 4 years in a selected population..$^{97,98}$
However, at the moment, the data available are not sufficient to demonstrate a significant difference between these two therapies in terms of survival. As previously pointed out, more than 1,000 patients would have to be recruited in order to power a head-to-head equivalence trial with TACE having overall survival as the main endpoint, and this would represent too large a sample even for a multicenter study. ${ }^{99}$

No significant difference in survival was reported in a retrospective study comparing 38 patients treated with TARE and 35 treated with TACE (median 8.0 months versus 10.3 months, respectively; $P=0.33$ ). ${ }^{100}$

Salem et $\mathrm{a}^{86}$, in a very large series of 463 patients, showed that median OS between TARE and TACE in the entire cohort - composed for $53 \%$ of intermediate-stage HCCs and for $35 \%$ of early-stage HCCs - was not significantly different (17.4 months for the TACE group and 20.5 months for the TARE group) and also similar in the subset of intermediate HCCs (17.5 months versus 17.2 months, $P=0.42$ ). However, in the subgroup of patients with inoperable early-stage HCC, they reported a longer median TTP after TARE of 25.1 months (95\% confidence interval [CI]: 8-27 months) as compared to TACE (8.8 months) and this may suggest a potential advantage of using TARE as a bridge therapy in patients waiting for liver transplantation (LT) ${ }^{73}$

The reason for the lack of significant data regarding comparison could be the well-known heterogeneity of the BCLC-B stage, which includes different tumor characteristics in terms of tumor number and size. ${ }^{88}$ In fact, TACE is not effective in large tumors, especially in the presence of multiple satellite nodules, and these patients often experience severe post-embolization syndrome; in this setting, TARE could be the first choice of treatment. It is necessary to assess

Table 5 Comparison of response and median survival after TARE and TACE

\begin{tabular}{|c|c|c|c|c|c|c|c|c|}
\hline $\begin{array}{l}\text { Study } \\
\text { (year) }\end{array}$ & Treatment & $\mathbf{N}$ & $\begin{array}{l}\text { OS } \\
\text { (months) }\end{array}$ & $\begin{array}{l}\text { TTP } \\
\text { (months) }\end{array}$ & $\begin{array}{l}\text { Response (CP/PR) \% } \\
\text { WHO/RECIST } \\
\text { criteria }\end{array}$ & $\begin{array}{l}\text { Response rate } \\
(\text { CP/PR) \% } \\
\text { EASL criteria }\end{array}$ & $\begin{array}{l}\text { Downstaged/ } \\
\text { LT \% }\end{array}$ & $\begin{array}{l}\text { Mean days in } \\
\text { hospital per } \\
\text { treatment }\end{array}$ \\
\hline Lewandowski & TARE (TheraSphere ${ }^{a}$ ) & 43 & 35.7 & 33.3 & 61 & 86 & $58^{c}$ & $0^{c}$ \\
\hline et $\mathrm{al}^{99}(2009)$ & TACE & 43 & 18.7 & 18.2 & 37 & 71 & 31 & 3 \\
\hline Kooby et al ${ }^{122}$ & TARE (SIR-Spheres $\left.{ }^{\mathrm{b}}\right)$ & 27 & 6 & NR & 11 & NR & NR & $1.7^{\mathrm{c}}$ \\
\hline$(2010)$ & TACE & 44 & 6 & & 6 & & & 6 \\
\hline Carr et al ${ }^{102}$ & TARE (TheraSphere ${ }^{a}$ ) & 99 & 11.5 & NR & 41 & $N R$ & $N R$ & NR \\
\hline$(2010)$ & TACE & 691 & 8.5 & & 60 & & & \\
\hline Salem et $a^{86}$ & TARE (TheraSphere ${ }^{a}$ ) & 123 & 20.5 & 13.3 & 49 & 72 & 25 & $0^{c}$ \\
\hline$(20 I I)$ & TACE & 122 & 17.4 & 8.4 & 46 & 69 & 36 & 1.8 \\
\hline
\end{tabular}

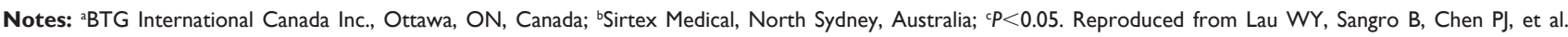
Treatment for hepatocellular carcinoma with portal vein tumor thrombosis: the emerging role for radioembolization using yttrium-90. Oncology. 20I3;84(5):3। I-3I8, with permission from S. Karger AG, Basel. ${ }^{125}$

Abbreviations: TARE, transarterial radioembolization; TACE, transarterial chemoembolization; OS, overall survival; TTP, time to tumor progression; CP, complete response; PR, partial response; WHO, World Health Organization; RECIST, Response Evaluation Criteria in Solid Tumors; EASL, European Association for the Study of the Liver; LT, liver transplantation; NR, not reported. 
a comparison between TARE and TACE in the same setting of tumor burden; moreover, it is also necessary to evaluate the cost-effectiveness of these two therapies considering, on the one hand, the higher cost of TARE and, on the other, the longer hospital stay and the cumulative charges involved in repeated TACE procedures.

In the downstaging setting, to reduce the tumor burden within acceptable limits for LT, to render non-operable patients operable, or to simplify surgery, TARE seems a promising therapy, due to its high potential to induce intense tumor responses. Furthermore, the advantage of pre-LT downstaging is to recognize patients with a favorable tumor biology with a reduced risk of recurrence after transplantation. Additionally, atrophy of the irradiated lobe after TARE and contralateral lobe hypertrophy as a result of lobar TARE, known as "radiation lobectomy"75 may contribute to resectability.

Several authors ${ }^{49,99,101-110}$ described their results of TARE in the treatment of HCC as a bridge therapy before resection or transplantation as compared to TACE. The preliminary study of Riaz et $\mathrm{al}^{49}$ of TARE performed prior to LT reported that none of the 15 patients progressed from United Network for Organ Sharing T2 to T3 during the waiting time, and eight out of ten were downstaged from the T3 to the T2 stage. Furthermore, at histology, 100\% necrosis was found in $89 \%$ of the lesions $<3 \mathrm{~cm}$ and $65 \%$ of the lesions $3-5 \mathrm{~cm}$ in size. The same authors and others had previously analyzed ${ }^{106,107}$ similar data in patients treated with TACE prior to LT, showing $35 \%-57 \%$ complete necrosis in lesions $<3 \mathrm{~cm}$ and $17 \%-42 \%$ in lesions $3-5 \mathrm{~cm}$ in size. ${ }^{107,109,110}$

Lewandowski et $\mathrm{al}^{99}$ in a retrospective analysis of patients with HCC beyond the Milan criteria preliminary to LT, among which as many as two-thirds were downstaged, showed that TARE achieved a better downstaging than TACE (58\% versus $31 \%, P=0.023$ ).

Ettorre et $\mathrm{al}^{103}$ reported their experience on 22 patients treated with TARE for HCC without extrahepatic spread not suitable either for resection nor for transplantation because they were outside the Milan criteria. After TARE, ten patients were successfully downstaged and transplanted 6 months after the treatment and one patient underwent a right hepatectomy. On the explanted livers, 60\% had an HCC within the Milan criteria and 30\% within the up-toseven criteria; $90 \%$ of patients did not show microvascular invasion. Nine patients are alive $(81.8 \%)$ without signs of recurrence. Complete necrosis was found in the $\mathrm{HCC}$ patient who underwent hepatectomy, who is still alive without recurrence.
Another study ${ }^{109}$ reported data coming from 20 patients transplanted following a ${ }^{90}$ Y-TARE downstaging, after a mean waiting time on the list of 3.5 months: at the moment of transplantation 16 patients (80\%) were successfully downstaged to Milan criteria. Histopathology of the explanted livers showed complete necrosis in five cases (25\%), 50\%-99\% of necrosis in six cases $(30 \%)$, and $<50 \%$ of necrosis in nine cases $(45 \%)$.

In the advanced stage HCC (BCLC-C), sorafenib is the currently recommended treatment ${ }^{5}$ and has been shown to improve survival in patients with or without PVTT; ;1,12 $^{2}$ however, it is not without severe side effects.

The median OS following TARE ranges from 6 to 10.4 months, ${ }^{61,62}$ very similar to the $6.5-10.7$ months of the SHARP and Asia-Pacific populations in the sorafenib registration trials. ${ }^{12,21}$

\section{TARE in BCLC-C stage patients with PVTT as an alternative to sorafenib}

The presence of PVTT is a contraindication to TACE but it is not a contraindication to TARE; there is increasing evidence that TARE can be delivered safely and effectively in this setting. Table 6 reports several studies with a median OS rate of approximately 10 months.

However, patients with main PVTT have a poor prognosis after TARE, with median OS ranging from 3 to 6 months, ${ }^{111,112}$, as compared to the median OS of patients with segmental or lobar PVTT (10-14 months). ${ }^{82,97}$ Patients with PVTT and Child-Pugh class B have a survival of 2-5 months ${ }^{10}$ due to liver decompensation. The extent of PVTT affects the prognosis of these patients; in a group of patients with Child-Pugh class A, the presence of branch involvement leads to a median OS of 16.6 months versus 7.4 months for those with main PVTT. ${ }^{62}$ In the same series, ${ }^{62}$ when patients in Child-Pugh class B disease with PVTT were analyzed, the median survival was only 5.6 months; in fact, in these patients, the risk of death is higher due to underlying liver disease rather than to tumor progression (median survival of 7.7 months for Child-Pugh class B disease despite a TTP of 8.4 months).

The ongoing Phase III trials (YES-P Trial [NCT 00537514] and STOP-HCC Trial [NCT01576490]) comparing TARE with sorafenib in locally advanced $\mathrm{HCC}$ will better define the role of these two therapeutic strategies in the advanced stage HCC.

To date, only one retrospective series with a propensity analysis ${ }^{113}$ has compared the outcomes of two groups of patients treated with TARE and sorafenib. As a result, considering all 
Table 6 Response and median survival after TARE in HCC with or without PVTT

\begin{tabular}{|c|c|c|c|c|c|}
\hline Study (year) & PVTT & $\mathbf{N}$ & $\begin{array}{l}\text { Response (CR/PR) \% } \\
\text { WHO/RECIST } \\
\text { criteria }\end{array}$ & $\begin{array}{l}\text { Response rate } \\
(\text { CR/PR) \% } \\
\text { EASL criteria }\end{array}$ & $\begin{array}{l}\text { OS } \\
\text { (months) }\end{array}$ \\
\hline Salem et al ${ }^{62}(2010)$ & Child-Pugh A & 116 & 52 & 69 & 17.2 \\
\hline TheraSphere $^{\mathrm{b}}$ & No PVTT & 81 & 53 & 77 & 22.1 \\
\hline \multirow[t]{8}{*}{ no EHS } & PVTT (mixed) & 35 & 50 & 50 & 10.4 \\
\hline & First-order & 19 & 58 & 58 & 16.6 \\
\hline & Main & 16 & 40 & 40 & 7.7 \\
\hline & Child-Pugh B & 122 & 39 & 52 & 7.7 \\
\hline & No PVTT & 65 & 47 & 67 & 14.8 \\
\hline & PVTT (mixed) & 57 & 28 & 32 & 5.6 \\
\hline & First-order & 27 & 28 & 40 & 6.5 \\
\hline & Main & 30 & 28 & 24 & 4.5 \\
\hline Hilgard et al ${ }^{61}(2010)$ & All pts & 108 & 15 & 40 & 16.4 \\
\hline TheraSphere ${ }^{\mathrm{b}}$ & No PVTT & 75 & NR & NR & 16.4 \\
\hline \multirow[t]{2}{*}{$30 \%$ EHS } & PVTT (mixed: main [12]; & 33 & & & 10 \\
\hline & First/second-order [12]; unknown [9]) & & & & \\
\hline Sangro et $\mathrm{al}^{10}(20 \mathrm{II})$ & All pts & 325 & NR & NR & 12.8 \\
\hline SIR-Spheres ${ }^{a}$ & No PVTT & 249 & & & 15.3 \\
\hline \multirow[t]{2}{*}{$9 \%$ EHS } & PVTT (mixed: main [32]); & 76 & & & 10.7 \\
\hline & First-order [44]) & & & & 9.7 \\
\hline Inarrairaegui et $\mathrm{al}^{63}(2010)$ & PVTT (mixed: main [6]; & 25 & NR & NR & 10 \\
\hline TheraSphere $^{\mathrm{b}}$ and SIR-Spheres ${ }^{\mathrm{a}}$ & First/second-order [19]) & & & & \\
\hline Tsai et al ${ }^{127}(2010)$ & PVTT & 22 & NR & NR & 7 \\
\hline TheraSphere $^{\mathrm{b}}$ and SIR-Spheres ${ }^{\mathrm{a}}$ & Main & 12 & & & 4.4 \\
\hline I3\% EHS & First-order & 10 & & & 7 \\
\hline Woodall et al ${ }^{112}(2009)$ & No PVTT & 20 & NR & NR & 13.9 \\
\hline TheraSphere ${ }^{b}$ & PVTT (mixed: main [10]) & 15 & & & 3.2 \\
\hline Kulik et al'"' (2008) & All pts & 108 & 42 & 70 & NR \\
\hline TheraSphere ${ }^{\mathrm{b}}$ & No PVTT & 71 & & & 15.4 \\
\hline \multirow[t]{2}{*}{$12 \%$ EHS } & PVTT main & 12 & & & 4.4 \\
\hline & First-order & 25 & & & 9.9 \\
\hline
\end{tabular}

Notes: aSirtex Medical, North Sydney, Australia; 'BTG International Canada Inc., Ottawa, ON, Canada. Reproduced from Lau WY, Sangro B, Chen PJ, et al. Treatment for hepatocellular carcinoma with portal vein tumor thrombosis: the emerging role for radioembolization using yttrium-90. Oncology. 20I 3;84(5):3II-3।8, with permission from S. Karger AG, Basel. ${ }^{125}$

Abbreviations: TARE, transarterial radioembolization; HCC, hepatocellular carcinoma; PVTT, portal vein tumor thrombosis; WHO, World Health Organization; RECIST, Response Evaluation Criteria in Solid Tumors; EASL, European Association for the Study of the Liver; OS, overall survival; EHS, extrahepatic disease; pts, patients; NR, not reported; CR, complete response; PR, partial response; main, main portal vein trunk; first-order, right and/or left portal vein; second-order, segmental branches of portal vein.

the patients deemed fit for both therapies, these therapies both provided similar survival; the median OS of the sorafenib arm was 13.1 months (95\% CI: 1.2-25.9) and of the TARE arm 11.2 months (95\% CI: $6.7-15.7 ; P=0.392)$, but only in the TARE arm two patients were fully downstaged to LT.

Memon et $\mathrm{al}^{114}$ have recently reported that detailed knowledge of the liver function and Child-Pugh status of the disease in the presence of PVTT and of progression after TARE is crucial for considering systemic therapy or additional clinical trials.

In advanced stage HCC, the presence of extrahepatic disease has been demonstrated to have a negative impact on survival after TARE; the median OS was 7.4 months in the European series ${ }^{10}$ and 5.4 months in the US series. ${ }^{61}$ This is the fundamental aim of the emerging studies on the combination of TARE and sorafenib. ${ }^{15-117}$
The combination of TACE with sorafenib has also been investigated; 7,14 it was safe, but its efficacy in improving tumor response and/or delaying tumor progression rate, and the best sequence of this association, have not yet been proven.

The first pilot randomized study, investigating the safety of combining TARE with sorafenib compared to TARE alone in 20 patients intended for LT, was recently published by Kulik et al. ${ }^{117}$ Seventeen patients underwent LT (nine patients in the TARE group and eight in the other arm). Although the limited sample prevented a strong conclusion, the combination of sorafenib to TARE did not appear to influence complete pathological necrosis, provided similar survival rates to LT $(70 \%$ and $72 \%$ at 3 years, respectively), and appeared to impact clinical outcomes with higher rates of post-transplant acute cellular rejection and biliary complications. 


\section{Conclusion and future prospects}

Potential indications for ${ }^{90} \mathrm{Y}$-TARE include the treatment of patients with: 1) intermediate stage HCC who are poor candidates for TACE due to numerous or bulky tumors; 2) advanced stage HCC with solitary tumors invading a segmental or lobar branch of the portal vein; 3) potential downstaging for a radical approach; and 4) disease progression requiring TACE or sorafenib.

The National Comprehensive Cancer Network and European Society of Medical Oncology guidelines recommend TARE as a "bridge" option before other treatment modalities (partial hepatectomy, LT), as the principal therapy for patients with diffuse intrahepatic tumor spread or as an alternative to TACE in selected patients with contraindications for TACE. ${ }^{110-119}$

However, even though the Consensus Recommendations of the National Cancer Institute Clinical Trials Planning Meeting ${ }^{120}$ stated that TARE may be used in selected patients with HCC without extrahepatic disease who are amenable to radical therapies, in the recently updated American Association for the Study of Liver Disease ${ }^{5}$ algorithms for the treatment of unresectable HCC, TARE is not considered as standard therapy for advanced HCC, which continues to "jump" between TACE and sorafenib. Large and relevant clinical trials are now underway to establish the precise roles of TARE in the treatment of HCC.

In particular, a number of multicenter randomized controlled trials regarding both the intermediate and the advanced stages of HCC are ongoing, stratifying patients with and without portal vein invasion. The PREMIERE trial (NCT00956930), a US randomized trial, compares TARE with radiofrequency ablation, TACE, or their combination in patients with unresectable HCC and well preserved liver function. To date, as described above, no significant differences between TACE and TARE have been found in terms of survival rates, but TARE seems to be significantly better tolerated regarding post-procedural abdominal pain, length of hospital stay, and post-embolization syndrome.

Taking into account the good toxicity profile of TARE and the well-established similar survival rates across different subgroups of patients, a number of multicenter randomized controlled trials are on-going in advanced-stage patients, either combining TARE with sorafenib or comparing TARE versus sorafenib. In both the Asia-Pacific SIRveNIB trial (NCT 01126645) and the European SORAMIC trial (NCT01126645), TARE and sorafenib are being compared in HCC patients without extrahepatic disease who are not suitable to TACE and also in HCC patients with extrahepatic disease. The trials are on-going but preliminary results report that TARE should be considered as good an option as sorafenib in the same setting of patients.

Another large prospective randomized clinical trial has recently begun comparing TARE with glass microspheres (TheraSphere ${ }^{\circledR}$ ) versus sorafenib for the treatment of advanced HCC with PVTT (Phase III Protocol TS-104); it involves up to 25 sites in Europe, Asia, and North America (YES-P trial NCT 00537514).

The SIRTACE study (NCT00867750), a European randomized trial, also analyses the quality of life (QoL) after TACE and TARE.

In a prospective study, Salem et al ${ }^{121}$ have recently analyzed the QoL in patients with HCC treated with TACE (29 patients) or with TARE (27 patients). They used the Functional Assessment of Cancer Therapy - Hepatobiliary (FACT-Hep) questionnaire, which is a 45-item self-report instrument specifically designed with patient and clinician input to measure health-related QoL in patients with hepatobiliary cancers. ${ }^{121}$ The authors concluded that patients treated with TARE had significant improvement in several aspects of QoL as compared to patients who underwent TACE. However, due to the limited sample size, there was no significant difference in overall FACT-Hep health-related QoL scores. Additional studies are needed to evaluate the influence on QoL of these therapies.

The last, but not least, important point to take into account is the cost and the availability of the TARE procedure. Kooby et al ${ }^{122}$ compared the costs of TARE to those of TACE, reporting the first to be less costly than multiple TACE sessions, especially if drug-eluting beads are used rather than the very expensive biological therapies.

In conclusion, TARE is a therapy which requires a multidisciplinary team of experts in order to guarantee the best patient selection and to perform the optimal procedure for each individual patient; therefore, this treatment should be restricted to tertiary level centers with certified expertise after thorough training of the staff.

\section{Disclosure}

The authors report no other conflicts of interest in this work.

\section{References}

1. Forner A, Llovet JM, Bruix J. Hepatocellular carcinoma. Lancet. 2012;379(9822):1245-1255.

2. Parkin DM, Bray F, Ferlay J, Pisani P. Global cancer statistics, 2002. CA Cancer J Clin. 2005;55(2):74-108. 
3. Bosch FX, Ribes J, Díaz M, Cléries R. Primary liver cancer: worldwide incidence and trends. Gastroenterology. 2004;127(5 Suppl 1): S5-S16.

4. Kudo M. Japan's successful model of nationwide hepatocellular carcinoma surveillance highlighting the urgent need for global surveillance. Liver Cancer. 2012;1(3-4):141-143.

5. Bruix J, Sherman M, American Association for the Study of Liver Diseases. Management of hepatocellular carcinoma: an update. Hepatology. 2011;53(3):1020-1022.

6. Llovet JM, Ducreux M, Lencioni R, et al. EASL-EORTC clinical practice guidelines: management of hepatocellular carcinoma. $J$ Hepatol. 2012;56(4):908-943.

7. Lencioni R. Chemoembolization in patients with hepatocellular carcinoma. Liver Cancer. 2012;1(1):41-50.

8. Llovet JM, Bruix J. Systematic review of randomized trials for unresectable hepatocellular carcinoma: chemoembolization improves survival Hepatology. 2003;37(2):429-442.

9. Kim DY, Ryu HJ, Choi JY, et al. Radiological response predicts survival following transarterial chemoembolisation in patients with unresectable hepatocellular carcinoma. Aliment Pharmacol Ther. 2012;35(11) 1343-1350.

10. Sangro B, Carpanese L, Cianni R, et al. Survival after yttrium-90 resin microsphere radioembolization of hepatocellular carcinoma across Barcelona clinic liver cancer stages: a European evaluation. Hepatology. 2011;54(3):868-878.

11. Llovet JM, Ricci S, Mazzaferro V, et al. Sorafenib in advanced hepatocellular carcinoma. N Engl J Med. 2008;359(4):378-390.

12. Cheng AL, Kang YK, Chen Z, et al. Efficacy and safety of sorafenib in patients in the Asia-Pacific region with advanced hepatocellular carcinoma: a phase III randomised, double-blind, placebo-controlled trial. Lancet Oncol. 2009;10(1):25-34.

13. Kudo M, Imanaka K, Chida N, et al. Phase III study of sorafenib after transarterial chemoembolization in Japanese and Korean patients with unresectable hepatocellular carcinoma. Eur J Cancer. 2011;47(14) 2117-2127.

14. Kudo M. Treatment of advanced hepatocellular carcinoma with emphasis on hepatic arterial infusion chemotherapy and molecular targeted therapy. Liver Cancer. 2012;1(2):62-70.

15. Choi GH, Shim JH, Kim MG et al. Sorafenib alone versus sorafenib combined with transarterial chemoembolization for advanced-stage hepatocellular carcinoma: results of propensity score analyses. Radiology. 2013;269(2):603-611.

16. Iavarone M, Cabibbo G, Piscaglia F, et al. Field-practice study of sorafenib therapy for hepatocellular carcinoma: a prospective multicenter study in Italy. Hepatology. 2011;54(6):2055-2063.

17. Uka K, Aikata H, Takaki S, et al. Clinical features and prognosis of patients with extrahepatic metastases from hepatocellular carcinoma. World J Gastroenterol. 2007;13(3):414-420.

18. Yoo DJ, Kim KM, Jin YJ, et al. Clinical outcome of 251 patients with extrahepatic metastasis at initial diagnosis of hepatocellular carcinoma: does transarterial chemoembolization improve survival in these patients? J Gastroenterol Hepatol. 2011;26(1):145-154.

19. Pinter M, Hucke F, Graziadei I, et al. Advanced-stage hepatocellular carcinoma: transarterial chemoembolization versus sorafenib. Radiology. 2012;263(2):590-599.

20. Senthilnathan S, Memon K, Lewandowski RJ, et al. Extrahepatic metastases occur in a minority of hepatocellular carcinoma patients treated with locoregional therapies: analyzing patterns of progression in 285 patients. Hepatology. 2012;55(5):1432-1442.

21. Bruix J, Raoul JL, Sherman M, et al. Efficacy and safety of sorafenib in patients with advanced hepatocellular carcinoma: subanalysis of a phase III trial. $J$ Hepatol. 2012;57(4):821-829.

22. Brown DB, Gould JE, Gervais DA, et al. Transcatheter therapy for hepatic malignancy: standardization of terminology and reporting criteria. J Vasc Interv Radiol. 2009;20(Supp1 7):S425-S434.

23. Sangro $B$, D'Avola $D$, Iñarrairaegui $M$, Prieto J. Transarterial therapies for hepatocellular carcinoma. Expert Opin Pharmacother. 2011;12(7): 1057-1073.
24. Bilbao JI, de Martino A, de Luis E, et al. Biocompatibility, inflammatory response, and recanalization characteristics of nonradioactive resin microspheres: histological findings. Cardiovasc Intervent Radiol. 2009;32(4):727-736.

25. Sangro B, Iñarrairaegui M, Bilbao JI. Radioembolization for hepatocellular carcinoma. J Hepatol. 2012;56(2):464-473.

26. Campbell AM, Bailey IH, Burton MA. Tumour dosimetry in human liver following hepatic yttrium-90 microsphere therapy. Phys Med Biol. 2001;46(2):487-498.

27. Sato K, Lewandowski RJ, Bui JT, et al. Treatment of unresectable primary and metastatic liver cancer with yttrium-90 microspheres (TheraSphere): assessment of hepatic arterial embolization. Cardiovasc Intervent Radiol. 2006;29(4):522-529.

28. MacKie S, de Silva S, Aslan P, et al. Super selective radio embolization of the porcine kidney with 90yttrium resin microspheres: a feasibility, safety and dose ranging study. $J$ Urol. 2011;185(1):285-290.

29. Wigg AJ, Palumbo K, Wigg DR. Radiotherapy for hepatocellular carcinoma: systematic review of radiobiology and modeling projections indicate reconsideration of its use. J Gastroenterol Hepatol. 2010;25(4):664-671.

30. Lawrence TS, Robertson JM, Anscher MS, Jirtle RL, Ensminger WD, Fajardo LF. Hepatic toxicity resulting from cancer treatment. Int J Radiat Oncol Biol Phys. 1995;31(5):1237-1248.

31. Emami B, Lyman J, Brown A, et al. Tolerance of normal tissue to therapeutic irradiation. Int J Radiat Oncol Biol Phys. 1991;21(1): 109-122.

32. Dawson LA, McGinn CJ, Normolle D, et al. Escalated focal liver radiation and concurrent hepatic artery fluorodeoxyuridine for unresectable intrahepatic malignancies. J Clin Oncol. 2000;18(11): 2210-2218.

33. Dawson LA, Normolle D, Balter JM, McGinn CJ, Lawrence TS, Ten Haken RK. Analysis of radiation-induced liver disease using the Lyman NTCP model. Int J Radiat Oncol Biol Phys. 2002;53(4): 810-821.

34. Coldwell D, Sangro B, Wasan H, Salem R, Kennedy A. General selection criteria of patients for radioembolization of liver tumors: an international working group report. Am J Clin Oncol. 2011;34(3): 337-341.

35. Salem R, Thurston KG. Radioembolization with 90Yttrium microspheres: a state-of-the-art brachytherapy treatment for primary and secondary liver malignancies. Part 1: Technical and methodologic considerations). J Vasc Interv Radiol. 2006;17(8):1251-1278.

36. Covey AM, Brody LA, Maluccio MA, Getrajdman GI, Brown KT. Variant hepatic arterial anatomy revisited: digital subtraction angiography performed in 600 patients. Radiology. 2002;224(2): 542-547.

37. Liu DM, Salem R, Bui JT, et al. Angiographic considerations in patients undergoing liver directed therapy. $J$ Vasc Interv Radiol. 2005;16(7): 911-935.

38. Murthy R, Nunez R, Szklaruk J, et al. Yttrium-90 microsphere therapy for hepatic malignancy: devices, indications, technical considerations, and potential complications. Radiographics. 2005;25 Suppl 1: S41-S55.

39. Ahmadzadehfar H, Biersack HJ and Ezziddin S. Radioembolization of liver tumors with yttrium-90 microspheres. Semin Nucl Med. 2010;40(2):105-121.

40. Chiesa C, Maccauro M, Romito R, et al. Need, feasibility and convenience of dosimetric treatment planning in liver selective internal radiation therapy with (90)Y microspheres: the experience of the National Tumor Institute of Milan. Q J Nucl Med Mol Imaging. 2011;55(2): 168-197.

41. Sangro B, Gil-Alzugaray B, Rodriguez J, et al. Liver disease induced by radioembolization of liver tumors: description and possible risk factors. Cancer. 2008;112(7):1538-1546.

42. Leung TW, Lau WY, Ho SK, et al. Radiation pneumonitis after selective internal radiation treatment with intraarterial 90yttrium-microspheres for inoperable hepatic tumors. Int J Radiat Oncol Biol Phys. 1995;33(4):919-924. 
43. Sirtex Medical Limited. Sirtex medical training manual, training program physicians and institutions. Australia. Available at: http://www. sirtex.com/usa/_data/page/549/TRN-US-0320for20US1.pdf. Accessed October 16, 2007.

44. Kennedy A, Nag S, Salem R, et al. Recommendations for radioembolization of hepatic malignancies using yttrium-90 microsphere brachytherapy: a consensus panel report from the radioembolization brachytherapy oncology consortium. Int J Radiat Oncol Biol Phys. 2007;68(1):13-23.

45. Gulec SA, Mesoloras G, Stabin M. Dosimetric techniques in 90Ymicrosphere therapy of liver cancer: The MIRD equations for dose calculations. J Nucl Med. 2006;47(7):1209-1211.

46. Strigari L, Sciuto R, Rea S, et al. Efficacy and toxicity related to treatment of hepatocellular carcinoma with 90Y-SIR spheres: radiobiologic considerations. J Nucl Med. 2010;51(9):1377-1385.

47. Garin E, Rolland Y, Boucher E, et al. First experience of hepatic radioembolization using microspheres labelled with yttrium-90 (TheraSphere): practical aspects concerning its implementation. Eur J Nucl Med Mol Imaging. 2010;37(3):453-461.

48. Salem R, Lewandowski RJ, Gates VL, et al. Research reporting standards for radioembolization of hepatic malignancies. J Vasc Interv Radiol. 2011;22(3):265-278.

49. Riaz A, Kulik L, Lewandowski RJ, et al. Radiologic-pathologic correlation of hepatocellular carcinoma treated with internal radiation using yttrium-90 microspheres. Hepatology. 2009;49(4):1185-1193.

50. Lencioni R, Llovet JM. Modified RECIST (mRECIST) assessment for hepatocellular carcinoma. Semin Liver Dis. 2010;30(1):52-60.

51. Bruix J, Sherman M, Llovet JM, et al. Clinical management of hepatocellular carcinoma. Conclusions of the Barcelona-2000 EASL conference. European Association for the Study of the Liver. J Hepatol. 2001;35(3):421-430.

52. Geschwind JF, Artemov D, Abraham S, et al. Chemoembolization of liver tumor in a rabbit model: assessment of tumor cell death with diffusion-weighted MR imaging and histologic analysis. J Vasc Interv Radiol. 2000;11(10):1245-1255.

53. Guo Y, Yaghmai V, Salem R, et al. Imaging tumor response following liver-directed intra-arterial therapy. Abdom Imaging. 2013;38(6): 1286-1299.

54. Weintraub JL, Salem R. Treatment of hepatocellular carcinoma combining sorafenib and transarterial locoregional therapy: state of the science. J Vasc Interv Radiol. 2013;24(8):1123-1134.

55. Carr BI. Hepatic arterial 90Yttrium glass microspheres (Therasphere) for unresectable hepatocellular carcinoma: interim safety and survival data on 65 patients. Liver Transpl. 2004;10(2 Suppl 1): S107-S110.

56. Lau WY, Leung WT, Ho S, et al. Treatment of inoperable hepatocellular carcinoma with intrahepatic arterial yttrium-90 microspheres: a phase I and II study. Br J Cancer. 1994;70(5):994-999.

57. Lau WY, Ho S, Leung TW, et al. Selective internal radiation therapy for nonresectable hepatocellular carcinoma with intraarterial infusion of 90yttrium microspheres. Int J Radiat Oncol Biol Phys. 1998;40(3): 583-592.

58. Cao X, He N, Sun J, et al. Hepatic radioembolization with Yttrium-90 glass microspheres for treatment of primary liver cancer. Chin Med J Engl. 1999;112(5):430-432.

59. Salem R, Lewandowski RJ, Atassi B, et al. Treatment of unresectable hepatocellular carcinoma with use of $90 \mathrm{Y}$ microspheres (TheraSphere): safety, tumor response, and survival. J Vasc Interv Radiol. 2005;16(12): 1627-1639.

60. Kennedy AS, Coldwell D, Nutting C, et al. Resin 90Y-microsphere brachytherapy for unresectable colorectal liver metastases: modern USA experience. Int J Radiat Oncol Biol Phys. 2006;65(2): 412-425.

61. Hilgard P, Hamami M, Fouly AE, et al. Radioembolization with yttrium-90 glass microspheres in hepatocellular carcinoma: European experience on safety and long-term survival. Hepatology. 2010;52(5): 1741-1749.

62. Salem R, Lewandowski RJ, Mulcahy MF, et al. Radioembolization for hepatocellular carcinoma using Yttrium-90 microspheres: a comprehensive report of long-term outcomes. Gastroenterology. 2010;138(1): 52-64.
63. Iñarrairaegui M, Thurston KG, Bilbao JI, et al. Radioembolization with use of yttrium-90 resin microspheres in patients with hepatocellular carcinoma and portal vein thrombosis. JVasc Interv Radiol. 2010;21(8): 1205-1212.

64. Lau WY, Sangro B, Chen PJ, et al. Treatment for hepatocellular carcinoma with portal vein tumor thrombosis: the emerging role for radioembolization using yttrium-90. Oncology. 2013;84(5):311-318.

65. Chan AO, Yuen MF, Hui CK, Tso WK, Lai CL. A prospective study regarding the complications of transcatheter intraarterial lipiodol chemoembolization in patients with hepatocellular carcinoma. Cancer. 2002;94(6):1747-1752.

66. Gaba RC, Riaz A, Lewandowski RJ, et al. Safety of yttrium-90 microsphere radioembolization in patients with biliary obstruction. J Vasc Interv Radiol. 2010;21(8):1213-1218.

67. Atassi B, Bangash AK, Lewandowski RJ, et al. Biliary sequelae following radioembolization with Yttrium-90 microspheres. JVasc Interv Radiol. 2008;19(5):691-697.

68. Young JY, Rhee TK, Atassi B, et al. Radiation dose limits and liver toxicities resulting from multiple yttrium-90 radioembolization treatments for hepatocellular carcinoma. J Vasc Interv Radiol. 2007;18(11): 1375-1382.

69. Carretero C, Munoz-Navas M, Betes M, et al. Gastroduodenal injury after radioembolization of hepatic tumors. Am J Gastroenterol. 2007;102(6):1216-1220.

70. Naymagon S, Warner RR, Patel K, et al. Gastroduodenal ulceration associated with radioembolization for the treatment of hepatic tumors: an institutional experience and review of the literature. Dig Dis Sci. 2010;55(9):2450-2458.

71. Murthy R, Brown DB, Salem R, et al. Gastrointestinal complications associated with hepatic arterial Yttrium-90 microsphere therapy. JVasc Interv Radiol. 2007;18(4):553-561.

72. Trotti A, Colevas AD, Setser A, et al. CTCAE v3.0: development of a comprehensive grading system for the adverse effects of cancer treatment. Semin Radiat Oncol. 2003;13(3):176-181.

73. Golfieri R, Bilbao JI, Carpanese L, et al. Comparison of the survival and tolerability of radioembolization in elderly vs younger patients with unresectable hepatocellular carcinoma. J Hepatol. 2013;59(4):753-761.

74. Jakobs TF, Saleem S, Atassi B, et al. Fibrosis, portal hypertension, and hepatic volume changes induced by intra-arterial radiotherapy with 90yttrium microspheres. Dig Dis Sci. 2008;53(9):2556-2563.

75. Gaba RC, Lewandowski RJ, Kulik LM, et al. Radiation lobectomy, preliminary findings of hepatic volumetric response to lobar yttrium-90 radioembolization. Ann Surg Oncol. 2009;16(6):1587-1596.

76. Dancey JE, Shepherd FA, Paul K, et al. Treatment of nonresectable hepatocellular carcinoma with intrahepatic $90 \mathrm{Y}$ - microspheres. $J \mathrm{Nucl}$ Med. 2000;41(10):1673-1681.

77. Geschwind JF, Salem R, Carr BI, et al. Yttrium-90 microspheres for the treatment of hepatocellular carcinoma. Gastroenterology. 2004; 127(5 Suppl 1):S194-S205

78. Salem R, Lewandowski R, Roberts C, et al. Use of Yttrium-90 glass microspheres (TheraSphere) for the treatment of unresectable hepatocellular carcinoma in patients with portal vein thrombosis. J Vasc Interv Radiol. 2004;15(4):335-345.

79. Salem R, Thurston KG, Carr BI, Goin JE, Geschwind JF. Yttrium-90 microspheres: radiation therapy for unresectable liver cancer. J Vasc Interv Radiol. 2002;13(9 Pt 2):S223-S229.

80. Steel J, Baum A, Carr B. Quality of life in patients diagnosed with primary hepatocellular carcinoma: hepatic arterial infusion of Cisplatin versus 90-Yttrium microspheres (Therasphere). Psychooncology. 2004;13(2):73-79.

81. Liu MD, Uaje MB, Al-Ghazi MS, et al. Use of Yttrium-90 TheraSphere for the treatment of unresectable hepatocellular carcinoma. Am Surg. 2004;70(11):947-953.

82. Lau WY, Ho S, Leung TW, et al. Selective internal radiation therapy for nonresectable hepatocellular carcinoma with intraarterial infusion of 90yttrium microspheres. Int J Radiat Oncol Biol Phys. 1998;40(3): 583-592. 
83. Mazzaferro V, Sposito C, Bhoori S, et al. Yttrium-90 radioembolization for intermediate-advanced hepatocarcinoma: A phase 2 study. Hepatology. 2013;57(5):1826-1837.

84. Weng Z, Ertle J, Zheng S, et al. A new model to estimate prognosis in patients with hepatocellular carcinoma after Yttrium-90 radioembolization. PLoS One. 2013;8(12):e82225.

85. Choi H, Charnsangavej C, Faria SC, et al. Correlation of computed tomography and positron emission tomography in patients with metastatic gastrointestinal stromal tumor treated at a single institution with imatinib mesylate: proposal of new computed tomography response criteria. J Clin Oncol. 2007;25(13):1753-1759.

86. Salem R, Lewandowski RJ, Kulik L, et al. Radioembolization results in longer time-to-progression and reduced toxicity compared with chemoembolization in patients with hepatocellular carcinoma. Gastroenterology. 2011;140(2):497-507.

87. Kolligs FT, Bilbao JI, Jakobs T, et al. SIRTACE: A randomised multicentre pilot trial of selective internal radiation therapy (SIRT) with yttrium-90 $\left({ }^{90} \mathrm{Y}\right)$ resin microspheres versus transarterial chemo-embolisation (TACE) in patients with unresectable hepatocellular carcinoma (HCC). Presented at: International Liver Cancer Association Seventh Annual Conference; September 13-15, 2013; Washington, DC. Abstract number: P-136.

88. Bolondi L, Burroughs A, Dufour JF, et al. Heterogeneity of patients with intermediate (BCLC B) Hepatocellular Carcinoma: proposal for a subclassification to facilitate treatment decisions. Semin Liver Dis. 2012;32(4):348-359.

89. Raoul JL, Sangro B, Forner A, et al. Evolving strategies for the management of intermediate-stage hepatocellular carcinoma: available evidence and expert opinion on the use of transarterial chemoembolization. Cancer Treat Rev. 2011;37(3):212-220.

90. D’Avola D, Iñarrairaegui M, Bilbao JI, Martinez-Cuesta A, et al. A retrospective comparative analysis of the effect of Y90-radioembolization on the survival of patients with unresectable hepatocellular carcinoma Hepatogastroenterology. 2009;56(96):1683-1688.

91. Llovet JM, Real MI, Montaña X, et al. Arterial embolisation or chemoembolisation versus symptomatic treatment in patients with unresectable hepatocellular carcinoma: a randomised controlled trial. Lancet. 2002;359(9319):1734-1739.

92. Lo CM, Ngan H, Tso WK, et al. Randomized controlled trial of transarterial lipiodol chemoembolization for unresectable hepatocellular carcinoma. Hepatology. 2002;35(5):1164-1171.

93. Cammà C, Schepis F, Orlando $\mathrm{A}$, et al. Transarterial chemoembolization for unresectable hepatocellular carcinoma: meta-analysis of randomized controlled trials. Radiology. 2002;224(1):47-54

94. Chen CH, Hu FC, Huang GT, et al. Applicability of staging systems for patients with hepatocellular carcinoma is dependent on treatment method-analysis of 2010 Taiwanese patients. Eur J Cancer. 2009; 45(9):1630-1639.

95. Lewandowski RJ, Mulcahy MF, Kulik LM, et al. Chemoembolization for hepatocellular carcinoma: comprehensive imaging and survival analysis in a 172-patient cohort. Radiology. 2010;255(3):955-965.

96. Wang JH, Changchien CS, Hu TH, et al. The efficacy of treatment schedules according to Barcelona Clinic Liver Cancer staging for hepatocellular carcinoma - Survival analysis of 3892 patients. Eur J Cancer. 2008;44(7):1000-1006.

97. Burrel M, Reig M, Forner A, et al. Survival of patients with hepatocellular carcinoma treated by transarterial chemoembolisation (TACE) using Drug Eluting Beads. Implications for clinical practice and trial design. J Hepatol. 2012;56(6):1330-1335.

98. Malagari K, Pomoni M, Moschouris H, et al. Chemoembolization with doxorubicin-eluting beads for unresectable hepatocellular carcinoma: five-year survival analysis. Cardiovasc Intervent Radiol. 2012;35(5):1119-1128.

99. Lewandowski RJ, Kulik LM, Riaz A, et al. A comparative analysis of transarterial downstaging for hepatocellular carcinoma: chemoembolization versus radioembolization. Am J Transplant. 2009;9(8): 1920-1928.
100. Lance C, McLennan G, Obuchowski N, et al. Comparative analysis of the safety and efficacy of transcatheter arterial chemoembolization and yttrium-90 radioembolization in patients with unresectable hepatocellular carcinoma. J Vasc Interv Radiol. 2011;22(12): 1697-1705.

101. Riaz A, Lewandowski RJ, Kulik L, et al. Radiologic-pathologic correlation of hepatocellular carcinoma treated with chemoembolization. Cardiovasc Intervent Radiol. 2010;33(6):1143-1152.

102. Carr BI, Kondragunta V, Buch SC, Branch RA. Therapeutic equivalence in survival for hepatic arterial chemoembolization and yttrium 90 microsphere treatments in unresectable hepatocellular carcinoma: a two-cohort study. Cancer. 2010;116(5):1305-1314.

103. Ettorre GM, Santoro R, Puoti C, et al. Short-term follow-up of radioembolization with yttrium-90 microspheres before liver transplantation: new perspectives in advanced hepatocellular carcinoma. Transplantation. 2010;90(8):930-931.

104. Kulik LM, Mulcahy MF, Hunter RD, Nemcek AA Jr, Abecassis MM, Salem R. Use of yttrium-90 microspheres (TheraSphere) in a patient with unresectable hepatocellular carcinoma leading to liver transplantation: a case report. Liver Transpl. 2005;11(9):1127-1131.

105. Kulik LM, Atassi B, van Holsbeeck L, et al. Yttrium-90 microspheres (TheraSphere) treatment of unresectable hepatocellular carcinoma: downstaging to resection, RFA and bridge to transplantation. J Surg Oncol. 2006;94(7):572-586.

106. Golfieri R, Cappelli A, Cucchetti A, et al. Efficacy of selective transarterial chemoembolization in inducing tumor necrosis in small $(<5 \mathrm{~cm})$ hepatocellular carcinomas. Hepatology. 2011;53(5):1580-1589.

107. Iñarrairaegui M, Pardo F, Bilbao JI, et al. Response to radioembolization with yttrium-90 resin microspheres may allow surgical treatment with curative intent and prolonged survival in previously unresectable hepatocellular carcinoma. Eur J Surg Oncol. 2012;38(7): 594-601

108. Tabone M, Calvo A, Viganò L, Ferrero A. Downstaging to liver resection by radioembolization: a difficult to reach strategy? Eur J Surg Oncol. 2013;39(8):918-919.

109. Ettorre GM, Laurenzi A, Vennarecci G. Downstaging Hepatocellular carcinoma with Yttrium-90 radioembolization: resection or transplantation? Eur J Surg Oncol. 2014;40(6):789-790.

110. Tohme S, Sukato D, Chen HW, et al. Yttrium-90 radioembolization as a bridge to liver transplantation: a single- institution experience. J Vasc Interv Radiol. 2013;24(11):1632-1638.

111. Kulik LM, Carr BI, Mulcahy MF, et al. Safety and efficacy of $90 \mathrm{Y}$ radiotherapy for hepatocellular carcinoma with and without portal vein thrombosis. Hepatology. 2008;47(1):71-81.

112. Woodall CE, Scoggins CR, Ellis SF, et al. Is selective internal radioembolization safe and effective for patients with inoperable hepatocellular carcinoma and venous thrombosis? J Am Coll Surg. 2009;208(3):375-382.

113. Gramenzi A, Golfieri R, Mosconi C, et al. Yttrium-90 radioembolization versus sorafenib for intermediate-locally advanced hepatocellular carcinoma: a cohort study with propensity score analysis. Liver Int. Epub April 22, 2014.

114. Memon K, Kulik L, Lewandowski RJ, et al. Radioembolization for hepatocellular carcinoma with portal vein thrombosis: impact of liver function on systemic treatment options at disease progression. J Hepatol. 2013;58(1):73-80.

115. Rana N, Ju AW, Bazylewicz M, et al. Yttrium-90 Radioembolization in Patients with Hepatocellular Carcinoma Who have Previously Received Sorafenib. Front Oncol. 2013;3:323.

116. Chow PK, Poon DY, Khin MW, et al. Multicenter phase II study of sequential radioembolization-sorafenib therapy for inoperable hepatocellular carcinoma. PLoS One. 2014;9(3):e90909.

117. Kulik L, Vouche M, Koppe S, et al. Prospective randomized pilot study of Y90+/-sorafenib as bridge to transplantation in hepatocellular carcinoma. J Hepatol. 2014;61(2):309-317. 
118. National comprehensive cancer network clinical practice guidelines in oncology. Hepatobiliary guidelines. V2.2010. Available from: http:// www.ncccn.org/professionals/physician_gls/PDF/hepatobiliary.pdf. http://www.jnccn.org/content/7/4/350.long. Accessed September 9, 2014.

119. Jelic S, Sotiropoulos GC, ESMO Guidelines Working Group. Hepatocellular carcinoma: ESMO Clinical Practice Guidelines for diagnosis, treatment and follow-up. Ann Oncol. 2010;21(Suppl 5): v59-v64.

120. Thomas MB, Jaffe D, Choti MM, et al. Hepatocellular carcinoma: consensus recommendations of the National Cancer Institute Clinical Trials Planning Meeting. J Clin Oncol. 2010;28(25):3994-4005.

121. Salem R, Gilbertsen M, Butt Z, et al. Increased quality of life among hepatocellular carcinoma patients treated with radioembolization, compared with chemoembolization. Clinl Gastroenterol Hepatol. 2013:11(10):1358-1365.

122. Kooby DA, Egnatashvili V, Srinivasan S, et al. Comparison of yttrium-90 radioembolization and transcatheter arterial chemoembolization for the treatment of unresectable hepatocellular carcinoma. J Vasc Interv Radiol. 2010;21(2):224-230.
123. Goin JE, Salem R, Carr BI et al. Treatment of unresectable hepatocellular carcinoma with intrahepatic yttrium 90 microspheres: a risk-stratification analysis. J Vasc Interv Radiol. 2005;16:195-203.

124. Gulec SA, Sztejnberg ML, Siegel JA, Jevremovic T, Stabin M. Hepatic structural dosimetry in (90)Y microsphere treatment: a Monte Carlo modeling approach based on lobular microanatomy. J Nucl Med. 2010;51(2):301-310.

125. Kim YH, Kim do Y. Yttrium-90 radioembolization for hepatocellular carcinoma: what we know and what we need to know. Oncology. 2013;84 Suppl 1:34-39.

126. Sangro B, Bilbao JI, Boan J et al. Radioembolization using 90 Y-resin microspheres for patients with advanced hepatocellular carcinoma. Inter J Radiat Oncol Biol Phys. 2006;55:792-800.

127. Tsai AL, Burke CT, Kennedy AS et al. Use of yttrium- 90 microspheres in patients with advanced hepatocellular carcinoma and portal vein thrombosis. J Vasc Interv Radiol. 2010;21:1377-1384.
Journal of Hepatocellular Carcinoma

\section{Publish your work in this journal}

The Journal of Hepatocellular Carcinoma is an international, peerreviewed, open access journal that offers a platform for the dissemination and study of clinical, translational and basic research findings in this rapidly developing field. Development in areas including, but not limited to, epidemiology, vaccination, hepatitis therapy, pathology and

\section{Dovepress}

molecular tumor classification and prognostication are all considered for publication. The manuscript management system is completely online and includes a very quick and fair peer-review system, which is all easy to use. Visit http://www.dovepress.com/testimonials.php to read real quotes from published authors. 